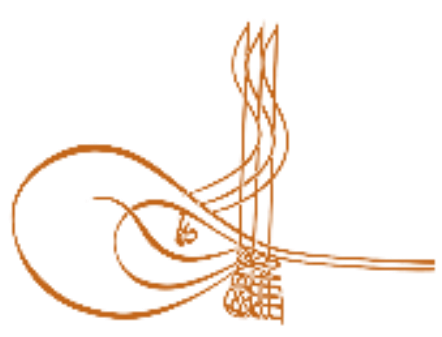

www.turkishstudies.net/social
Turkish Studies - Social Sciences

eISSN: $2667-5617$

Research Article / Araștırma Makalesi

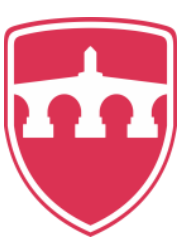

INTERNATIONAL

BALKAN

UNIVERSITY

Sponsored by IBU

\title{
Popüler Görsel Kültürde Toplumsal Cinsiyet Rollerinin İncelenmesi: Youtube Kanallarında Kadın ve Erkek İmajları
}

\author{
Investigation Of Gender Roles In Popular Visual Culture: Images Of Women And Men In Youtube \\ Channels
}

\author{
Ebru Güler* - Mehtap Uludağ ${ }^{* *}$
}

\begin{abstract}
This study aims at investigating the gender roles through "YouTube" and "youtubers", used and followed by Generation Z, who were born into and grown up in the popular visual culture of the digital World. The study is a qualitative research. The study was conducted in the art painting workshop course in Erzincan Binali Yıldırım University Fine Arts Training Department. The participants of the study are comprised of $2^{\text {nd }}$ year prospective teachers of the art painting workshop. Three survey sheets "Perceptions of Images of Women and Men in Social Media", "Structured Interview Form for Perceptions of Images of Women and Men in Social Media", and "Concept Map for Images of Women and Men", prepared by the researchers, were used as data collection tools. The data in the study were analyzed using the descriptive analysis method. When the findings of the study are considered, it is seen that a great majority of the prospective teachers related women with cosmetic products, chores, cooking and charm, while they related men with science, power, intelligence and freedom. The pre-service teachers stated that female YouTubers should do video content on make-up, food, personal care rather than on science, technology and art. It is notable that the pre-service teachers have gender stereotypes about the video contents of female and male YouTubers. It is seen that prospective teachers had a sexist perspective and adopted the roles related to certain cultural and traditional values.
\end{abstract}

Structured Abstract: The images and videos that were not previously accessed easily by everyone can be now accessed, reproduced and shared by people through web-sites thanks to today's technology. Today, web-sites such as YouTube, Facebook and etc., are visited by millions of people and push them into a stack of images. It is widely accepted that these mass media tools emit messages, which inevitably play a role in

\footnotetext{
* Dr. Öğr. Üyesi, Erzincan Binali Yıldırım Üniversitesi, Eğitim Fakültesi, Güzel Sanatlar Eğitimi Bölümü Asst. Prof. Dr., Erzincan Binali Ylldirım University, Faculty of Education, Department of Fine Art Education ORCID 0000-0003-1149-6489

ebrucigir8987@gmail.com

***äksek Lisans Öğrencisi, Erzincan Binali Yıldırım Üniversitesi, Eğitim Fakültesi, Güzel Sanatlar Eğitimi Bölümü.

Graduate Student, Erzincan Binali Ylldrtm University, Graduate School of Social Sciences, Department of Fine Art

Education
}

ORCID 0000-0002-9236-7058

mehtapuludag86@gmail.com

Cite as/ Atıf: Güler, E., Uludağ M. (2020). Popüler görsel kültürde toplumsal cinsiyet rollerinin incelenmesi: Youtube

kanallarında kadın ve erkek imajları, Turkish Studies - Social, 15(1), 343-367.

https://dx.doi.org/10.29228/TurkishStudies.37844

Received/Geliş: 27 September/Eylül 2019

Accepted/Kabul: 25 February/Şubat 2020

Copyright (C) INTAC LTD, Turkey

Checked by plagiarism software

Published/Yayın: 29 February/Şubat 2020

CC BY-NC 4.0 
the society (Tüzel, 2010:693). Individuals must be visual literate to correctly interpret and make sense of the messages continuously emitted by the mass media.

The roles imposed on people through the media under the influence of popular culture restrict what individuals can do and turn the mass media into a tool that serves the purpose of popular culture. The mass media, which have become a tool for popular culture, shape gender roles under the influence of popular culture and feed on visuals that occupy everywhere. It is critical to raise awareness on this issue among today's youth called Generation Z, born and raised in a digital age and appearing to be different from previous generations, as they have virtual environment in the center of their lives (Cited from Somyürek, 2014:66). To create social awareness on gender roles, formed by the mass media tools and popular culture, it is pre-requisite to determine the society's awareness of this issue. In doing so, popular culture, the media and mass media tools, which unite the society on a common ground, can be good tools. Among them, one of the most widely used tools is YouTube. The majority of Generation Z, born and raised into the digital world, spends time on YouTube. This generation, who follows what their peers do during the day, produces fun videos matching the trends of the day and watches such videos by subscribing to the different channels available on YouTube. This study recognizes this ease of accessibility in today's world and analyses gender roles and images created through "YouTube and YouTuber" that appear to be one of the elements of popular visual culture via media.

As qualitative research, this study uses descriptive analysis method. The participants of this study are the pre-service teachers who are in the second year of study at the Department of Art Teaching, the Faculty of Education, in Erzincan Binali Y1ldırım University in the 2018-2019 academic year. A total of 16 pre-service teachers, of whom 9 are male and 7 are female, participated in the study.

The data are collected through three different worksheets including "Perception on female and male images on social media", "Structured interview form on the perception of female and male images on social media" and "Concept Map." In the worksheet "Perception on female and male images on social media", the following three questions are asked to the participants based on 9 visuals selected from trending YouTube videos: "What do you see in these images? What kind of images do the figures in these images show? Please write the words that come to your mind when you look at these images." These three questions are intended to reveal the perceptions of the pre-service teachers on female and male images. The second worksheet "Structured interview form on the perception of female and male images on social media" consists of 12 structured interview questions. By using the third worksheet, the participants are shown 6 examples from trending YouTube channels and trending YouTubers and asked to form a "concept map on female and male images" during the course of Main Art Workshop.

The findings of the study show that the pre-service teachers generally adopted a sexist perspective in their perceptions on female and male images in the statements they gave based on the visuals intended to reveal their perceptions on female and male images. They also had a cultural and traditional perspective on gender. The perceptions of the pre-service teachers focused on beauty, attention, attractiveness, cosmetics and cleavage; they also emphasized that women have greater power than men in terms of economy. As they pointed out, the reason for this is that women are more favoured in the capitalist sector due to commercial concerns such as advertisements. The pre-service teachers assessed female images in the emotional dimension as well and used the concepts of attractive, cunning, self-confident and happy. The concepts used by the pre-service teachers in their expressions on male images were not used by them in their expressions on female images. The teachers featured scientificness and intelligence in their expressions on male images. They used the concepts of angry, free, crazy, courageous while assessing male images in the emotional dimension. It is notable that the statements of the pre-service teachers on the visuals featuring LGBT particularly emphasized the issue of ethics. The pre-service teachers also expressed that one's gender preference should comply with the gender roles determined by the society, otherwise s/he would be excluded by the society. Some teachers also highlighted the importance of the society on gender preference. After assessing the visuals featuring LGBT in the economic dimension, the teachers concluded that promotional videos and YouTube are a source of income for the LGBT individuals. In the emotional dimension, they defined these individuals as delicate, sensitive and courageous.

Keywords: Popular Visual Culture, Gender, Image, Generation Z. 
Öz: $\mathrm{Bu}$ araştırmada popüler görsel kültür içerisinde dijital dünyanın içinde doğup büyüyen z kuşağının çoğunlukla kullandığı ve takip ettiği “youtube ve youtuberlar" üzerinden toplumsal cinsiyet rollerinin incelenmesi amaçlanmıştır. Araştırmada nitel araştırma yaklaşımı benimsenmiştir. Araştırma 2018-2019 bahar döneminde Erzincan Binali Yıldırım Üniversitesi Güzel Sanat Eğitimi Bölümünde resim anasanat atölye dersinde uygulanmıştır. Araştırma katılımcılarını resim anasanat atölye 2. sınıf öğretmen adaylarından 16 kişi oluşturmaktadır. Araştırmada veri toplama aracı olarak araştırmacılar tarafından hazırlanan "Sosyal medyada kadın ve erkek imajlarına ilişkin algı?” çalışma yaprağı, "Sosyal medyada kadın ve erkek imajlarına ilişkin algıya yönelik yapılandırılmış görüşme formu" ve "Kadın ve erkek imajlarına yönelik kavram haritası" olmak üzere üç adet çalışma yaprağı hazırlanmıştır. Araştırmada veriler betimsel analiz yöntemi ile çözümlenmiştir. Araştırma bulgularına bakıldığında, öğretmen adaylarının çoğunluğunun toplumsal cinsiyet rolleri içinde kadına yönelik algılarında kadını, güzellik ve bakım ürünleri, ev işleri, yemek ve çekicilik gibi özelliklerle öne çıkarırken, erkeği bilim, güç, zekâ ve özgür olması ile öne çıkarmışlardır. Öğretmen adayları kadın youtuberların video içerikleri arasında bilim, teknoloji, sanat gibi konuların yerine makyaj, yemek, kişisel bakım video içeriklerinin yer alması gerektiğini ifade etmişlerdir. Öğretmen adaylarının kadın ve erkek youtube video içeriklerinde toplumsal cinsiyet kalıp yargılara sahip oldukları görülmüştür. Öğretmen adaylarının cinsiyetçi bir bakış açısı sergiledikleri ve özellikle birtakım kültürel ve geleneksel değerlere ilişkin rolleri benimsedikleri görülmüştür.

Anahtar Kelimeler: Popüler Görsel Kültür, Toplumsal Cinsiyet, İmaj, Z kuşağı.

\section{Giriş}

İnsanlığın var oluşundan beri insanın etrafındaki görseller teknolojinin gelişimiyle paralel olarak hızla artmış ve bugün etraf görsellerle kuşatılmıştır. Görsellerin artışındaki bu hıza başta matbaa ardından kitle iletişim araçları ve kişisel bilgisayarların keşfi etki etmiştir denebilir (Parsa,2007:1). Geçmiş yıllarda herkesin kolayca ulaşamadığ1 fotoğraf ve görüntüler bugünün getirmiş olduğu teknoloji sayesinde insanlar tarafindan kolaylıkla ulaşılabilmekte, çoğaltılabilmekte ve siteler üzerinden paylaşım yolu ile yayılabilmektedir. Bugün kitle iletişim aracı olarak youtube, facebook vb siteler milyonlarca insanlar tarafından ziyaret edilmekte ve kişiyi görseller yığının içerisine atmaktadır. Tüm bu kitle iletişim araçlarının iletiler yaydığı ve bu iletilerin pek çok açıdan toplum içerisinde yadsınamaz bir rolü olduğu herkes tarafindan kabul edilen bir görüştür (Tüzel, 2010:693). Kitle iletişim araçlarının aralıksız yaydığı iletileri doğru olarak anlamlandırabilmek ve yorumlayabilmek için bireylerin görsel okuryazar olmaları gerekmektedir. Bu bağlamda görsel kültür kavramı karşımıza çıkmaktadır. Görsel olan, görünen işlevsel yâda iletişimsel bir değeri olan aynı zamanda estetik bir amacı olan her şeydir. Görsel olanın içerisine alan daha geniş bir kavram ise görsel kültür kavramıdır (Barnard, 2002). Mamur (2015:30)'a göre görsel kültür geleneksel sanat formlarından tema parklara, alışveriş merkezlerinden popüler sanatlara insan yapımı her şeyi temsil edebilen geniş bir kavramdır. Bu geniş kavram medya, kitle iletişim araçları, reklam, film, bilgisayar vb. kısacası görüntü ile ilgili her kavramı kapsam alanı içerisine almaktadır. Bu geniş kapsamlı kavram görsellerle birlikte üretici ile tüketiciyi çoğu kez karşı karşıya bırakmakta bu bırakılış ortamı ise Gronbeckin John Fiskeden aktardığı şekliyle popüler kültür kavramını ortaya çıkarmaktadır (Mutlu, 2005:367).

Popüler kültür en yalın haliyle halka ait olandır. Çünkü popüler kültür kavramı içerisindeki üretici ve tüketiciyi var eden halktır. Fakat popüler kavramı halk tarafından çoğunluk tarafindan sevilen veya seçilen anlamında kullanılmış örneğin popüler TV programı, popüler film yıldızı, popüler sporcu gibi kavramlar şeklinde hayatımızda yer almıştır. Popüler kültürde sürekli bir değişim söz konusudur örneğin müzik alanında popülerlik top10 listeleriyle, giyimde moda ile, yemek sektöründe Pepsi, Coco Cola, Pizza King, McDonals gibi markalarla kendini sürekli yenileyen değişimlerle var eder. $\mathrm{Bu}$ açıdan popüler kültür hızlı üretim ve tüketim kültürüdür. Popüler ürünler tüketici tarafından alınır kullanılır böylece tüketici tüketilenin popüleşmesini sağlar. Popülerlik tüketici açısından önemlidir çünkü eğer tüketici popülerliği yakalayamazsa popüler bir şekilde tedirgin edilir ve kendini tedirgin hisseder. Popülerliği takip eden tüketici ise 
mutlu olur popülerle kendini bulur (Erdoğan, 2004:4). Popülerlik bu açıdan toplum için önemlidir. Kitle iletişim araçlarının ve popüler kültürün ihtiyaçlarını karşılamada bir araç olarak kullanılması ve toplumsal cinsiyet rollerinin de bu amaca hizmet ettirilerek toplumdaki var olan algiy1 değiştirmesi konusunda bireyler bilinçlendirilmeli ve bu konuda farkındalık mutlaka topluma kazandıılmalıdır. Gerek bu konudaki farkındalığın kazandırılması gerekse kitle iletişim araçlarının aralıksız iletilerinin bireyler tarafindan doğru algılanması ve teknolojinin doğru kullanılması okuryazarlık eğitiminin gerekliliğini ve önemini arttırmaktadır. Bu gereklilik görsel kültür eğitimini zorunlu kılmaktadır. Günlük yaşamımızda karşılaştığımız görüntüler ve izlediğimiz her şeyden anlık olarak etkilendiğimizi düşünürüz. Aslında o anlık görüntüler bizim düşünce yapımızı ve hayatı anlamlandırmamızda büyük rol oynar. Toplumların sahip olduğu gelenek ve kültürel değerler yine toplumlar tarafindan üretilen yazınsal ve görsel imgelerle şekillenir. Görsel kültür üretilen bu yazınsal ve görsel imgelerle ilgilenir. Görsel kültürün incelediği konu bileşenlerinden birisi de cinsiyettir. Günümüz görüntülerinin yeni teknolojiler ile üretilip toplumlara sunulduğunu düşündüğümüzde kitle iletişim araçları öne çıkmaktadır. Mora'na (2005:4) göre kitle iletişim araçları cinsiyetçiliğin yeniden üretilmesi ve topluma ulaştırmada ya da var olan anlayışın değiştirilmesinde rol oynayan en önemli ve etkili bir yoldur. $\mathrm{Bu}$ durum toplumsal ve kültürel kimliğimizi yeni baştan gözden geçirmemizi gerekli kılmıştır.

Günümüzde medya önemli bir güç olarak karşımıza çıkmakta popülerliğin sürekliliği ve kapitalizmin geniş kitlelere yayılmasında da bir araç olarak kullanılmaktadır. Bu sistem içerisinde işgücü ve tüketici olarak kadın ve erkeğe belli roller yüklemiştir (Fidan, 2000:122). Bu cinsiyetçi yaklaşım karşımıza toplumsal cinsiyet kavramını çıkarmakta medyanın etki gücü ve popüler kültürün etkisi altında kişilere yüklemiş olduğu rollerin bilinmesi bu konuda farkındalığın kişilerce kazandırılması önem arz etmektedir. $\mathrm{Bu}$ açıdan toplumsal cinsiyet ve toplumsal cinsiyet kavramlarının iyi bir şekilde anlaşılması gerekmektedir. Cinsiyet, cinsler arasındaki biyolojik farkları açıklarken, toplumsal cinsiyet toplumsal olarak inşa edilmiş cinsler arasındaki kültürel yönden faklılıkları açıklar (Serdaroğlu, 2010:7). Toplumsal cinsiyet kavramına ilişkin olarak yapılan açıklamalara bakıldığında cinsler arasındaki kültürel ve sosyal yönden yüklenmiş sorumluluklar ve roller arasındaki ilişki olarak veya cinslerin toplum içerisinde üstlenmiş oldukları rollerin ve sorumlulukların kendi kendine var olmasından çok belirlenmiş olan roller ve sorumluluklar olduğu söylenebilir. Toplumsal cinsiyet rolleri ise cinsiyetçi bir tavır içerisinde kadına ve erkeğe ilişkin nasıl davranması gerektiğini, yapması gerek ve yapmaması gerekenleri belirler. Bir şekilde doğrudan ya da dolaylı yollarla belirlenen bu cinsiyet rolleri kişinin toplumda kabul görmesini kendini toplumun bir parçası olarak düşünebilmesini ona ait olduğunu hissedebilmesini sağlar (Aksoy, 2006:28-32).

Medya içerisinde her yayının cinsiyet rollerine ilişkin kendine has bir yaklaşımı vardır. $\mathrm{Bu}$ yayınlar içerisinde erkek egemen bir yaklaşımın yanında kadın egemen bir yaklaşımla da hareket edebilmektedir. Medya tüm bu yaklaşımının içerisinde yeni bir cinsiyet algı yaratabilir ve var olan algıyı değiştirebilir (Ersoy Çak, 2010:105). Bu durum medya üzerinden toplumsal cinsiyet algılarının incelenmesi üzerine yapılan araştırmaların önemi arttırabilir. Popüler kültürün etkisi altında medya üzerinden insana yüklenen roller bireylerin yapabilecekleri konusunda kisitlamakta kitle iletişim araçlarını popüler kültürün amacına hizmet eden bir kuklaya dönüştürmektedir. Popüler kültürün kuklası haline gelen kitle iletişim araçları, popüler kültürün etkisinde cinsiyet rollerine etki ederken beslendiği kaynak günümüzde ise her yeri işkal eden görseller olarak karşımıza çıkmaktadır. Kitle iletişim araçlarının ve popüler kültür olgusunun toplumu yönlendirme etkisinin önüne geçebilir. Bu konudaki farkındalık özellikle z kuşağı olarak adlandırılan dijital bir çağda doğmuş ve büyümüş olan ve önceki nesillerden farklılaştığı öngörülen günümüz gençliğine kazandırılması hayatının merkezinde sanal ortamın oturması bakımından oldukça önemli olabilir (Akt.Somyürek, 2014:66). Kitle iletişim araçları ve popüler kültürün oluşturduğu toplumsal cinsiyet rollerinde toplumsal bilincin oluşması için öncelikle bu konuda toplumun sahip olduğu farkındalık tespit edilmelidir. Bu tespitin yapılmasında toplumu ortak bir noktada birleştiren 
popüler kültür, medya ve kitle iletişim araçları iyi birer araç olabilirler. Bu araçlardan en yaygın olarak kullanılanlardan birisi ise youtube'tur.

Günümüzde en çok tanınan bir video paylaşım sitesi olan youtube 2005 yılında Jawed Karim, Chad Hurley ve Steve Chen tarafindan televizyonda kaçırdıkları proğramları yeniden izleye bilmeleri amacıyla kurulmuştur. Amarika Bileşik Devletlerinde kurulan youtube 2006 y1lında google tarafından satın alınarak hılı bir şekilde büyümüş yayılmış ve popülerlerşmiştir. Mayfield'in 2008 'de yaptığ 1 araştırmaya göre Youtube dünyanın dört bir yanında her gün yüz milyondan fazla izlenmektedir. 2013 yılında youtube'un izlenme süresi 6 milyar saatken, 2017 verilerine göre youtubenin izlenmesindeki bu süre 30 milyar saate çıkmıştır. Bu inanılmaz artış ve izlenme oranı youtubenin araştırmanın odak nokrası haline getirerek inceleme alanı olarak seçilmesine neden olduğu söylenebilinir. Bu site kullanıcılarına adeta sınırsız paylaşım alanı sunarken aynı zamanda kullanıcıyı hem üretici hemde tüketici olma firsatını da sağlayabilmekte. Bu durum youtube'un popüler kültüre hizmet eden konumuna getirirken kullanıcıyı ise görsel evrenin başrolü konumuna getirmektedir.Burada kullanıcılar kendi yayın akışlarını oluşturabilmekte, esne ve anternatif bir televizyon izleme biçimi oluşturabilmektedir. (Yıldırım, 2018 s:149). Dijital dünyanın içinde doğup büyüyen z kuşağının büyük bir çoğunluğu youtube'da zaman geçirmektedir. Kendi yaşıtlarının gün içerisinde ne yaptıklarını takip eden bu nesil günün trendlerine uygun olarak eğlenceli videolar ürettiği gibi youtube'da var olan farklı içerikli kanallara abone olarak izleyebilmektedirler. Bu erişebilirlik durumu göz önünde bulundurularak oluşturulan araştırmada, medya üzerinden günümüz toplumunun popüler görsel kültürü oluşturan öğelerden birisi olarak karşımıza çıkan "Youtube ve Youtuber" üzerinden oluşturulmak istenilen toplumsal cinsiyet rolleri ve imajları incelenmiştir. Bu bağlamda araştırmada görsel sanatlar eğitimi alan öğretmen adaylarının farkındalığının ne boyutta olduğunu ortaya koymak amaciyla öğretmen adaylarınıntoplumsal cinsiyet rollerine ilişkin görüşleri, youtube ve youtuberların oluşturduğu kadın ve erkek imajları, imajların cinsiyete göre farklılıkların neler olduğu incelenmiştir.

Kitle iletişim araçları üzerinden toplumsal cinsiyet rollerine ilişkin algılarının belirlendiği birçok araştırma yapılmıştır (Güllüoğlu Ö., 2004; Mora N., 2005; Yüksel, N. A., 2006; Velikuluçay ve diğerleri, 2007; Kalan Ö.G., 2010; Öngen B., Aytaç S.,2013; Cangöz İ. 2013; Akmeşe Z., Deniz K., 2015; Etiler N., Zengin Ü., 2015; Boylu ve diğerleri,2016; Elgün A., Alemdar M.Y, 2017). Bu araştırmalara bakıldığında medya, kitle iletişim araçları üzerinden toplumun cinsiyet rollerine ilişkin algılar saptanmaya çalışılmıştır. İlgili araştırmalara tartışma ve sonuç bölümünde ayrıntılı olarak yer verilmiştir.

\section{Yöntem}

Görsel sanatlar eğitimi alan 2. sınıf resim iş öğretmenliğinde öğrenim gören öğretmen adaylarının youtube ve youtuberlar üzerinden toplumsal cinsiyet rollerine ilişkin görüşlerinin belirlenmesi ve cinsiyet yönünden bakış açılarının belirlemesini amaçlayan bu çalışmada nitel araştırma yöntemi benimsenmiştir. Nitel araştırma gözlemciyi dünyanın tam ortasına koyan yerleşik bir aktivitedir. Nitel araştırma, dünyayı görünür hale getiren bir dizi yorumlayıcı, materyal uygulamalrından oluşur. Bu uygulamalar dünyayı dönüştürür. Bu uygulamalar dünyayı; alan notları, mülakatlar, konuşmalar, fotoğraflar, kayıtlar ve kendinize yazdığınız notları içeren bir temsiller serisine dönüştürür (Denzin ve Lincoln, 2011; akt. Bütün ve Demir, 2013:43).

\section{Veri analizi}

Araştırmada betimsel analiz yöntemi kullanılmıştır. Betimsel analiz, araştırmada kullanılan gözlem, görüşme ve doküman gibi veri toplama araçlarında yer alan soru, konu ya da temalar ele alınarak analiz edilir. Betimsel analiz, doğrudan alıntılar ile beslenir ya da desteklenir. Betimsel analiz doğrudan bir konun resmedilmesini, tanımlanmasını ve açıklanmasını amaçlar (Ekiz, 2013:75). Araştırmada katılımcılara verilen üç çalışma yaprağı analiz edilmiştir. Katılımcılara 
verilen üç çalışma yapră̆ında yer alan soru ve görsellere ilişkin görüşlerin frekans ve yüzdeleri alınarak yorumlanmıştır.

\section{Katılımcilar}

Araştırma katılımcılarını 2018-2019 eğitim-öğretim yılında Erzincan Binali Yıldırım Üniversitesi Eğitim Fakültesi Resim İş Öğretmenliğinde öğrenim gören 2. sınıf öğretmen adaylarından oluşmaktadır. Araştırmaya resim iş öğretmen adaylarından 9 erkek ve 7 kadın olmak üzere 16 öğretmen adayı katılmıştır. Araştırmaya katılan öğretmen adaylarına, kendi isimleri yerine kod isim verilmiştir. Araştırma öncesi öğretmen adaylarına araştırma gönüllü katılım formu verilerek araştırmanın amacı açıklanmış ve araştırmaya katılma durumlarına göre katılımcılar belirlenmiştir.

\section{Veri Toplama Araçları}

Resim iş öğretmenliği 2. sınıf öğretmen adaylarının toplumsal cinsiyet algılarının belirlenmesine ve cinsiyet imajlarına ilişkin görüşlerinin alınması amacıyla araştırmacılar tarafından hazırlanan "Sosyal medyada kadın ve erkek imajlarına ilişkin algı?" çalışma yaprağı, "Sosyal medyada kadın ve erkek imajlarına ilişkin algıya yönelik yapılandırılmış görüşme formu" ve "Kavram Haritası" olmak üzere üç adet çalışma yaprağı hazırlanmıştır. "Sosyal medyada kadın ve erkek imajlarına ilişkin algı?" çalışma yaprağında yer alan trend youtube videolarından seçilen 9 görsel üzerinden yöneltilen "Görsellerde ne görüyorsunuz?, Görsellerdeki figürler ne tür bir imaj sergilemektedir?, Görsellere ilişkin aklınıza gelen kelimeleri yazınız? sorular çerçevesinde öğretmen adaylarının kadın ve erkek imajlarına ilişkin algılarının ne olduğu belirlenmeye çalışılmıştır. İkinci çalışma yaprağı olan "Sosyal medyada kadın ve erkek imajlarına ilişkin algıya yönelik yapılandırılmış görüşme formu" ise 12 adet yapılandırılmış görüşme sorularına yer verilmiştir. Bu sorularda erkek ve kadın imajlarının nasıl algılandığı, youtuber'ların işledikleri konular, yaşam şekilleri, giyim tarzları, konuşma şekilleri vb. konularla ilgili görüşlerini belirlemek amaçlanmıştır. Üçüncü çalışma yaprağında ise anasanat atölye dersinde öğretmen adaylarına trend youtube kanalları ve trend youtuberlardan 6 örnek gösterilerek "Kadın ve erkek imajlarına yönelik kavram haritası" oluşturmaları istenmiştir. Öğretmen adaylarında izledikleri videolar ve çalışma yaprağında yer alan görsellere ilişkin akıllarına gelen kelimeleri yazmaları istenmiştir. Her bir öğretmen adayı "erkek" ve "kadın" iki ana kelimeden yola çıkarak bu kelimelere ilişkin çağrışımlarda bulunmuşlardır. Araştırmada çalışma yapraklarının geçerliliği ve güvenirliği için iki uzman sanat eğitimcisinin görüşü alınmıştır.

\section{Bulgu ve Yorumlar}

\section{Kadın ve Erkek İmajlarına Yönelik Kavram Haritasına İlişkin Bulgular}

Araştırmada öğretmen adaylarına sosyal medyada yer alan birçok kadın ve erkek görseli gösterilmiştir. Farklı içerik ve konularda yer alan kadın ve erkek görsellerinden 10 görsel araştırmacılar tarafından rastgele seçilerek öğretmen adaylarından her bir görsel için kavram haritası ile düşünceleri belirlenmiştir. Tablo 1'de öğretmen adaylarının kadın ve erkek görsellerine yönelik algıları gösterilmiştir. 
Tablo 1: Resim İş Öğretmen Adaylarının Youtuber Görsellerine Yönelik Erkek ve Kadın İmaj Algilar1

\begin{tabular}{|c|c|c|}
\hline Kadın görselleri ve İmaj & Erkek görselleri ve İmaj & LGBT görselleri \\
\hline $\begin{array}{l}\text { - Kadın } \\
\text { Güzellik } \\
\text { Boya } \\
\text { Dekolte } \\
\text { Kozmetik } \\
\text { Makyaj } \\
\text { - } \quad \text { Ekonomik Boyut } \\
\text { Güç } \\
\text { Maddiyat } \\
\text { Reklam } \\
\text { Pazarlama } \\
\text { Para } \\
\text { Ürün } \\
\text { Marka } \\
\text { - Duygusal boyut } \\
\text { Heyecanlı } \\
\text { Havalı } \\
\text { Çekicilik } \\
\text { Kurnaz } \\
\text { Özgüven } \\
\text { Mutluluk } \\
\\
\text { Modern Yaşam } \\
\text { Değişim } \\
\text { Popüler } \\
\text { Burjuva }\end{array}$ & $\begin{array}{l}\text { • } \quad \text { Erkek } \\
\text { Zekâ } \\
\text { Sayısal } \\
\text { Düsünce } \\
\text { Araştırmacı } \\
\text { Bilim adamı } \\
\text { Profesör } \\
\text { Öğretmen } \\
\text { Bilim } \\
\text { Başarı } \\
\text { Tarih } \\
\text { - } \quad \text { Ekonomik Boyut } \\
\text { Para } \\
\text { Bilgilendirme } \\
\text { Tanıtım videoları } \\
\text { - } \\
\text { Duygusal Boyut } \\
\text { Sakin } \\
\text { Öfke } \\
\text { Sinir } \\
\text { Deli } \\
\text { Hırslı } \\
\text { Esir } \\
\text { Serseri } \\
\text { Bencil } \\
\text { Teknoloji ve Oyun } \\
\text { Teknoloji } \\
\text { Çete } \\
\text { Rekortmen } \\
\text { Eğlenceli } \\
\text { Bağımlılık ve oyun }\end{array}$ & $\begin{array}{c}\text { - } \quad \text { Kadın İmajı } \\
\text { Makyaj } \\
\text { Güzellik } \\
\text { Kadınsal } \\
\text { - Cinsiyet Tercihi } \\
\text { Değişim } \\
\text { İsimlendirme } \\
\text { Eşcinsel } \\
\text { Hormon } \\
\text { Etkilenme } \\
\text { - Ekonomik Boyut } \\
\text { Kerimcan } \\
\text { Para } \\
\text { Youtube } \\
\text { Tanitım } \\
\text { videoları } \\
\\
\text { Duygusal boyut } \\
\text { Cesaret } \\
\text { Mutlu } \\
\text { Narin } \\
\text { Çekici } \\
\text { Ahlak }\end{array}$ \\
\hline
\end{tabular}

Öğretmen adaylarının kadın ve erkek imajlarına yönelik görüşlerinin alınması amacıyla yönlendirilen görsellere ilişkin öğretmen adaylarının ifadelerinde genel anlamda kadın ve erkeğe yönelik algılarında cinsiyetçi bir bakış açısı sergiledikleri görülmüştür. Toplumsal cinsiyet açısından ise kültürel ve geleneksel bir bakış açısı sergilemiş̧lerdir. Öğretmen adaylarının kadın imajına yönelik algılarında güzellik, ilgi, çekicilik, kozmetik, dekolte kavramlarına yer veren öğretmen adayları ekonomik boyutta kadının erkeklerden daha büyük bir güce sahip olduğunu vurgulamışlardır. Bunun nedenini ise kapitalist sektörde reklam vb. ticari kaygılardan dolayı kadının daha çok tercih edildiğine dikkat çekmişlerdir. Öğretmen adayları ifadelerinde kadını duygusal boyuttada değerlendirmiş ve bu boyutta çekici, kurnaz, özgüven sahibi, mutlu kavramlarını kullanmayı tercih etmişlerdir. Ayrıca kadının modern yaşamda yer aldığı ve burjuva sınıfını temsil ettiği görüşü öğretmen adaylarının vermiş olduğu ifadelerde geçmektedir. Öğretmen adaylarının yönlendirilen görsellere ilişkin ifadelerine erkek imajı açısından bakıldığında ise durum çok farklı bir şekil almıştır. Öğretmen adayları erkek imajı için bilimselliği ve zekâyı ön plana çıkarmıştır. Duygusal boyutta erkek imajını değerlendirirken ifadelerinde öfkeli, özgür, deli, cesaretli kavramlarını kullanmışlardır. Kadına modern yaşam kategorisinde değerlendiren öğretmen adayları erkek imajı için bu kategori yerine kadın imajında yer almayan teknoloji ve oyun kategorisinde değerlendirme yaparak teknolojiyi seven ve düşkün olan, erkeklerin bu konuda güçlü 
olduğunu ifadelerde geçen rekortmen kelimesinden anlaşılmaktadır. Bu kategoride erkeklerin eğlenceli olduğu, bağımlılık derecesinde erkeklerin bu kategoriyle ilgilendiğini ifade etmişlerdir. LGBT görsellerine ilişkin öğretmen adaylarının ifadelerine ve değerlendirmelerine baktığımızda ögretmen adaylarının özellikle ahlak konusunu ön plana çıkarmaları dikkat çekmiştir. Öğretmen adayları cinsiyet tercihinin toplumun belirlemiş olduğu cinsiyet rollerine uygun olması gerektiği aksi taktirde toplum tarafından dışlanılacağına yönelik ifadelerde bulunmuşladır. Cinsiyet tercihleri konusunda toplumun önemini vurgulayan ifadelere de rastlanılmıştır. LGBT görselleri ekonomik boyutta değerlendiriken tanıtım videoları ve youtube'un lgbt'liler için bir gelir kaynağı olarak görmüşlerdir. Duygusal boyutta ise narin, hassas ve cesaretli olarak tanımlamışlardır.

\section{Sosyal Medyada Yer Alan Kadın ve Erkek İmajlarına İlişkin Görüşler}

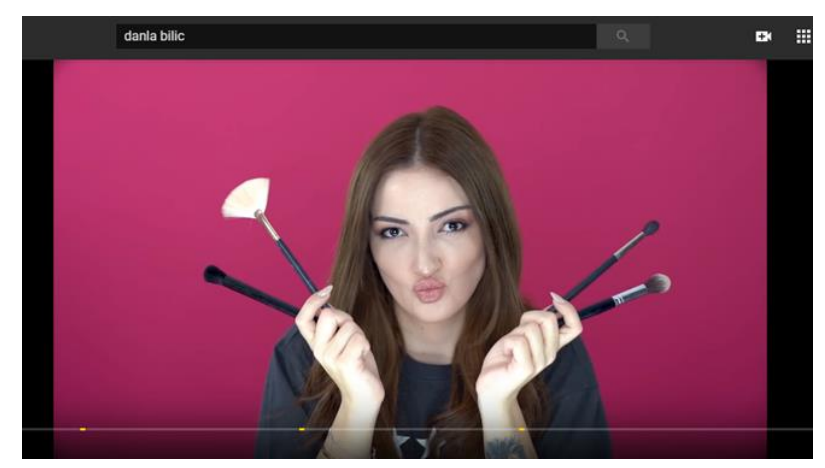

Görsel 1: Danla Bilic, Youtuber, Makyaj.

Kaynak: https://www.youtube.com/results?search_query=damla+bilic

Tablo 2: Öğretmen adaylarının "Danla Biliç" Görseline Yönelik Erkek ve Kadın İmajları

\begin{tabular}{lc}
\hline Bakış Açısı & Frekans \\
\hline & \\
Makyaj kadın imajına aittir & 4 \\
Güzellik kadın içindir & 7 \\
Kadın dikkat çekicidir & 3 \\
Makyajın kadının ilgi alanı olduğu & 3 \\
Kadını kadın anlar görüşü & 6 \\
\hline Toplam & $\mathbf{2 3}$ \\
\hline
\end{tabular}

Öğretmen adaylarının gösterilen youtuber görsellerine ilişkin vermiş oldukları cevaplardan 16 katılımcı içerisinden 4 kişi yöneltilen sorulara makyajı sadece kadın yapar cevabını vermiştir. Katılımcılardan 7 kişi kadın güzel olmaya çalışır çünkü güzellik kadın içindir cevabını vermiştir. Katılımcılardan 3 kişi kadının dikkat çekici olduğu cevabını vermiştir. Katılımcılardan 3 kişi makyajın sadece kadınların ilgilendiği bir alan olarak ifade ederken, 6 kişi makyaj videolarının kadınlar tarafından çekilmesi gerektiğini çünkü kadınları hemcinsleri tarafından daha iyi anlaşılacağı cevabını vermiştir. Öğretmen adaylarının görüşleri şu şekildedir: "Makyaj videolarının kadın imajında verilmesi dikkat çekiciliği arttırır (Selim)". "Görseldeki kadın modern ve çağdaş bir kadın profili sergiliyor. Ama dini açıdan baktığımızda toplumun dinsel olarak zedelendiğini görüyoruz (Veli)". Görseldeki figür makyaj ve bakım ile ilgili youtube videoları çeker. Toplumsal olarak baktığımız zaman kadın figürlerinin makyaja olan ilgisini attırmaktadır (Aleyna)". "Ülkemizde kadınlar kendi bakımlarına daha çok önem verdiği için hedef kitlesi kadın ve kadın ürünleri oluyor ve bu yolla ekonomik kazanç sağlanılıyor. (Metin)". "Bu youtuber makyaj uygulamaları yapıyor burada kadının rolü sadece makyaj yapan, süslü giyinen bir imaj çizdiriyor 
(İsmail)". Öğretmen adaylarına sorulan sorulara ilişkin alınan cevaplarda öğretmen adaylarının çoğunluğunun kadına yönelik algılarında kadınları güzellik ve bakım ürünleri ile özdeştirmişlerdir.

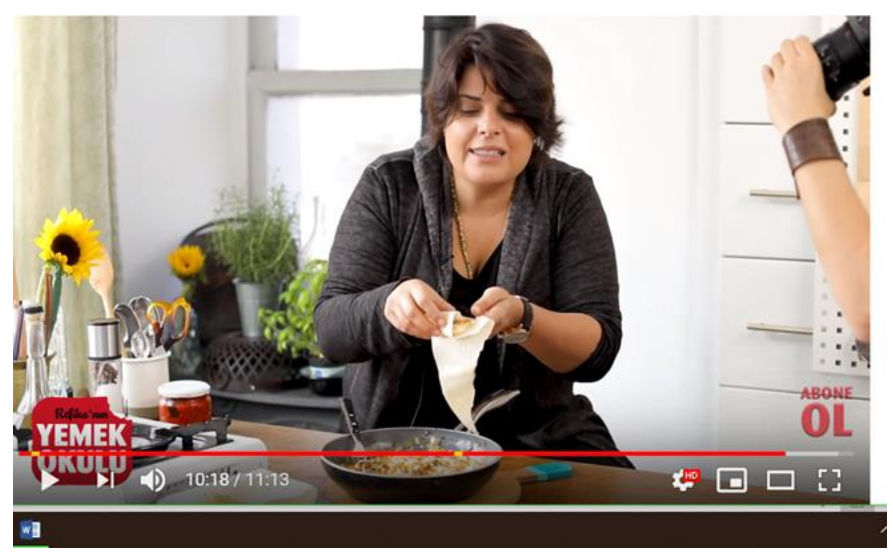

Görsel 2: Refikanın Mutfağı, Youtuber, Yemek ve Mutfak

Kaynak:https://www.youtube.com/results?search_query=refika\%27n\%C4\%B1n+mutfa\%C4\%9F\%C4\%B1

Tablo 3: Öğretmen Adaylarının "Refikanın Mutfăğ” Görseline Yönelik Erkek e Kadın İmajları

\begin{tabular}{ll}
\hline Bakış Açısı & Frekans \\
\hline Yalnızca kadın yemek yapmalı & 6 \\
Yemek konusu herkesi ilgilendirir & 2 \\
Kadın için yemek örnek bir imaj değildir & 4 \\
Yemek videoları kadın izleyici kitlesinin ilgisini çeker & 3 \\
Kadın sadece yemek ve ev işleri ile ilgilenmeli görüşü & 3 \\
\hline
\end{tabular}

Toplam 15

Öğretmen adaylarının gösterilen youtuber görsellerine ilişkin vermiş oldukları cevaplardan 16 katılımcı içerisinden 6 kişi yöneltilen sorulara ev hanımları (kadın) yemek yapmalı bundan dolayı yemek videoları kadın tarafından ele alınmalı cevabını vermiştir. Katılımcılardan 2 kişi vermiş olduğu cevaplarda yemek konusunun yalnızca kadını değil kadın kadar erkeği de ilgilendirdiğini ifade ermiştir. Katılımcılardan 4 kişi kadın için yemek yapmanın iyi bir imaj olmadığı cevabını verirken, Katılımcılardan 3 kişi yemek videolarının kadın tarafından ilgi çektiğini çünkü yemek konusunun kadını ilgi alanı olduğu cevabını vermiştir. Öğretmen adaylarının görüşleri şu şekildedir: "Yemek videolarının çekilmesi kadına yüklenen kadın yemek yapmalı görüşünü ön plana daha çok çıkarır ve vurgular (Selim)". "Hitap ettiği kitle kadın ve erkektir. Yemek konusu herkesi ilgilendirir. (Veli)". "Toplumsal sınıfın kadınların ev işlerine yakın olduğu, iş ayrımı yapıldığını kadınların ya makyaj ya da yemek yaptığını görüyorum. Bu ise erkek egemen toplumun youtube kanallarındaki yansımasını gösteriyor (Aleyna)". "Kadın yemek konusu ile daha çok ilgilenmeli çünkü tüm gün evde duran ve yemeği hazırlayan kadındır (Kadir)". "Öğretmen adaylarına sorulan sorulara ilişkin alınan cevaplarda öğretmen adaylarının çoğunluğunun kadına yönelik algılarında kadınları ev işleri ve yemek ile özdeştirmişlerdir. Bu durum öğretmen adaylarının kadın ve erkeğe yönelik geleneksel toplumsal cinsiyet rollerine sahip olduğunu göstermektedir. 


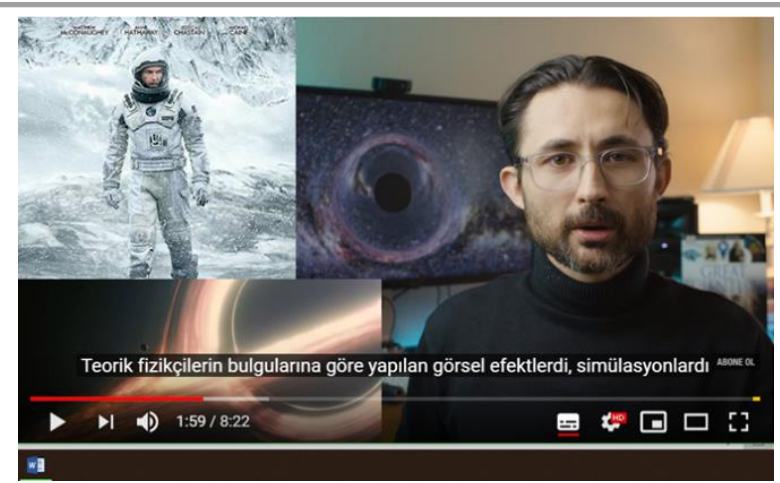

Görsel 3: Barı̧̧ Özcan, Youtuber, Bilim/Sanat/Teknoloji

Kaynak:https://www.youtube.com/results?search_query=bar\%C4\%B1\%C5\%9F+\%C3\%B6zcan+

Tablo 4: Öğretmen Adaylarının "Barıș Özcan" Görseline Yönelik Erkek ve Kadın İmajları

\begin{tabular}{lc}
\hline Bakış Açısı & Frekans \\
\hline & \\
Bilim ve araştırma konusu kadın imajında yer almaz & 5 \\
Bilim Adamı & 3 \\
Görseldeki ast rotun erkek olarak algılanması & 3 \\
\hline Toplam & $\mathbf{1 1}$ \\
\hline
\end{tabular}

Öğretmen adaylarının gösterilen youtuber görsellerine ilişkin vermiş oldukları cevaplardan 16 katılımcı içerisinden 5 kişi yöneltilen sorulara bilim ve araştırma konusunun kadın için uygun olmadığını bu gibi konuların erkeklerin ilgi alanı olduğu cevabını vermiştir. Katılımcılardan 3 kişi vermiş olduğu cevaplarda bilim adamı kelimesini kullanarak bilim alanıyla erkek ilgilenir yaklaşımını benimsedikleri anlaşılmaktadır. Katılımcılardan 3 kişi görselde yer alan astronotun erkek olduğunu ifade ederek astronot mesleğinin sadece erkek cinsi tarafından yapılabileceği görüşünü destekler nitelikte cevaplar vermişlerdir. Öğretmen adaylarının görüşleri şu şekildedir: "Bu resimde bilim adamına benzeyen biri var. Bilim ve bilgi hakkında video paylaşıyor. (Selim)". "Bilgi erkeklerin daha çok dikkatini çeker çünkü erkek bilgiyi hayatının her yerinde kullanır kadın evde olduğu için bilgiyi kullanacak ortam bulamaz bu yüzden bilimle erkek ilgilenmeli bilim videolarını da erkekler çekmeli (Ahmet)". "Erkek her zaman kadına göre daha zekidir yoksa bu videoları yapan kadın youtuberlar da olurdu ama yok (Rabia)". "Bu resimde bir erkek ve bilim teknoloji hakkında bilgi verir. Erkeklerin olması her zaman daha iyidir (Hüseyin)". "Öğretmen adayları sorulan sorulara ilişkin alınan cevaplarda kadını bilgi, bilim ve araştırma ile özdeştirmemişlerdir. Bu durum öğretmen adaylarının kadına ve erkeğe yönelik algılarında toplumsal cinsiyet rollerine göre bir düşünce oluşturduklarını göstermektedir. 


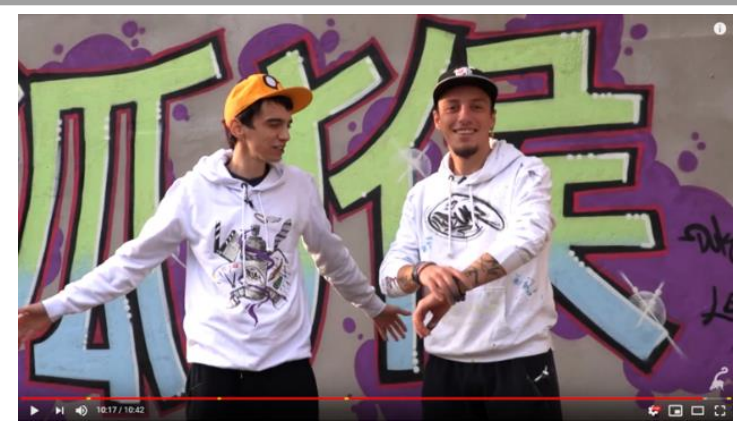

Görsel 4: Doğukan Oraklı, Youtuber, Sanat

Kaynak: https://www.youtube.com/results?search_query=do\%C4\%9Fukan+orak1\%C4\%B1

Tablo 5: Öğretmen Adaylarının "Doğukan Oraklı" Görseline Yönelik Erkek ve Kadın İmajları

\begin{tabular}{ll}
\hline Bakış Açısı & Frekans \\
\hline Kadın özgür değildir & 3 \\
Grafiti sanatı kadın imajında yer almaz & 5 \\
Sokak erkeğe aittir & 3 \\
\hline Toplam & $\mathbf{1 1}$ \\
\hline
\end{tabular}

Öğretmen adaylarının gösterilen youtuber görsellerine ilişkin vermiş oldukları cevaplardan 16 katılımcı içerisinden 3 kişi yöneltilen sorulara kadının özgür olmadığı bu yüzden sokakta özgürce grafiti sanatını yapamayacağı cevabını vermiştir. Katılımcılardan 5 kişi yöneltilen sorulara grafitiyi sadece erkekler yapar cevabını cevabını vermiştir. Katılımcılardan 3 kişi sokaklarda yapılan bir sanatın anacak erkekler tarafından yapılabileceği çünkü kadının sokaklarda özgür olamayacağı cevabını vermiş̧tir. Öğretmen adaylarınıngörüşleri şu şekildedir: "İnsanların yaşayış tarzını ele alırsak erkek çocuklar dışarıda sokakta özgür yaşıyor bu da duvar resimleri olsun futbol oyunu olsun erkeklere hitap ediyor. Hiç kadın grafiticiye rastlamadım (Selim)". "Sokak sanatı olan grafitiyi sadece erkekler yapıyor kadınlar neden yapmıyor anlamıyorum sanat kadın erkek demeden var olmalı (Asl1)". "Kadın özgür olmalı ki sokaklara çıkabilsin ve böyle sanat dallarına yönelsin (Halime)". Öğretmen adaylarına sorulan sorulara ilişkin alınan cevaplarda öğretmen adaylarının çoğunluğunun kadına yönelik algılarında özgürlük ve sokak sanatlarını kadın ile özdeşleştirememiştir. Bu bağlamda öğretmen adaylarının kadın ve erkek imajlarını algılayışlarında erkek egemen bir anlayıș benimsediklerini söyleyebiliriz. Öğretmen adayları özellikle sanat alanında kadınların geri planda olması gerektiğini vurgulamışlardır. Görsel sanatlar eğitimi alan öğretmen adaylarının bu şekilde düşünmeleri ilgi çekicidir. Bu durum sosyal medyanın cinsiyet rollerine yönelik algıları nasıl etkilediğini ve şekillendirdiğini göstermektedir. 


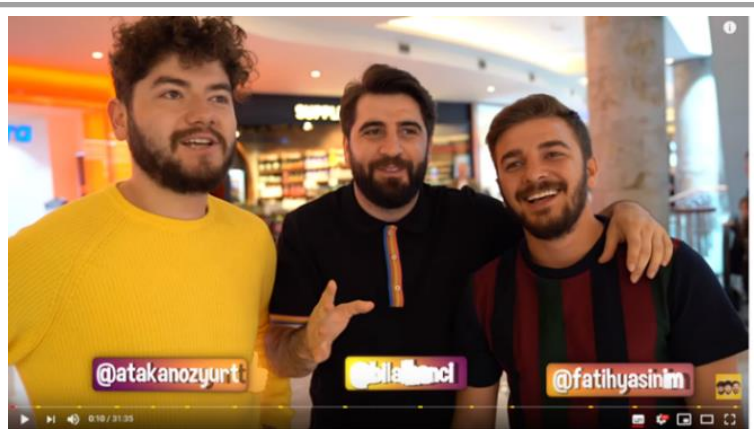

Görsel 5: Atakan Özyurt, Bilal Hanc1, Fatih Yasin Youtuber, Eğlence

Kaynak: https://www.youtube.com/results?search_query=kafalar

Tablo 6: Öğretmen adaylarının "Kafalar" görseline yönelik erkek ve kadın imajları

\begin{tabular}{ll}
\hline Bakış Açısı & Frekans \\
\hline Eğlence erkek ve kadın imajında ortak olmalı & 2 \\
Eğlence içerikleri erkekler tarafindan ele alınmalı & 4 \\
Kadınların erkekler kadar rahat hareket etmedikleri & 2 \\
\hline Toplam & $\mathbf{1 1}$ \\
\hline
\end{tabular}

Öğretmen adaylarının gösterilen youtuber görsellerine ilişkin vermiş oldukları cevaplardan 16 katılımcı içerisinden 2 kişi eğlence içerikli videoların ortak ele alınması gerektiği kadın ve erkek olarak ayrılmaması gerektiği cevabını vermiştir. Katılımcılardan 4 kişi yöneltilen sorulara eğlence içerikli videoların erkekler tarafından ele alınması gerektiğine çünkü erkek youtuberların video içeriklerinin daha çeşitli olduğu kadınların ise makyaj, yemek, moda gibi kendi ilgi alanlarına yönelik videolarla sınırlı kaldıkları bu yüzden içeriklerinin çeşitli olmadığı cevabını vermiştir. Katılımcılardan 2 kişi yöneltilen sorulara kadının özgür olmadığı bu yüzden görselde yer alan youtuberların videolarındaki rahatlığın kadın youtuberlar da olmayacağı cevabını vermiştir. Öğretmen adaylarınıngörüşleri şu şekildedir: "Buradaki erkek imajında gece hayatı ve eğlenceli videolar çekilirken çok rahat davranışlar segilenirken kadınlar bu kadar rahat hareket edemez (Selim)". Öğretmen adaylarına sorulan sorulara ilişkin alınan cevaplarda öğretmen adaylarının çoğunluğunun kadına yönelik algılarında özgürlük ve eğlence kavramlarını kadın ile özdeşleştirememiştir. Öğretmen adaylarının görüşlerine bakıldığında erkek ve kadın imajlarına yönelik algılarına sosyal medyanın ciddi bir yönlendirmesinin olduğu sonucuna varılabilir. Ayrıca ataerkil bir toplum yapısının yansıması görülmektedir.

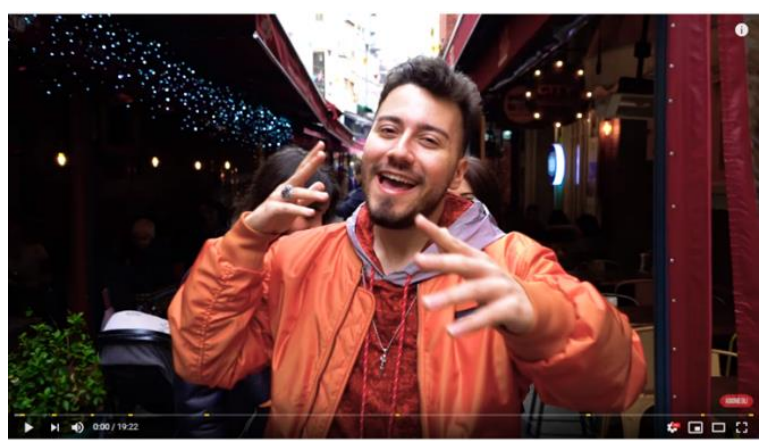

Görsel 6: Enes Batur, Youtuber, Eğlence

Kaynak: https://www.youtube.com/results?search_query=enes+batur

Turkish Studies - Social, 15(1) 
Tablo 7: Öğretmen Adaylarının "Enes Batur” Görseline Yönelik Erkek ve Kadın İmajları

Bakış Açısı $\quad$ Frekans

Sokak röportaj videoları erkek tarafindan çekilmeli 2

Erkekler kadınlardan daha cesaretlerdir $\quad 2$

Kadın erkek kadar özgür değildir 3

$\begin{array}{ll}\text { Toplam } & 7\end{array}$

Öğretmen adaylarının gösterilen youtuber görsellerine ilişkin vermiş oldukları cevaplardan 16 katılımcı içerisinden 2 kişi sokak röportajlarının erkeklerin daha cesaretli olmasından dolayı erkekler tarafından çekilmesi gerektiği cevabını vermiştir. Katılımcılardan 2 kişi yöneltilen sorulara kadınların erkekler kadar cesaretli olmadığı cevabını vermiştir. Katılımcılardan 3 kişi yöneltilen sorulara kadının erkekler kadar özgür olmadığı cevabını vermiştir. Öğretmen adaylarının görüşleri şu şekildedir: "Erkekler kadınlardan daha cesaretli oldukları için sokak röportajlarında erkekler daha çok görülür (Selim)". "Görseldeki erkeğin haretleri çok rahat kadınlar bu kadar rahat olamaz (Aykut)". "Kadın röportaj yapan çok az neden az bilmiyorum ama hiçbir şeyin erkek kadın olarak eşit yapılması gerekir (Damla)". Öğretmen adaylarına sorulan sorulara ilişkin alınan cevaplarda öğretmen adaylarının çoğunluğunun kadına yönelik algılarında cesaret ve röportaj kavramlarını kadın ile özdeşleştirememişlerdir. Öğretmen adaylarının yaklaşımlarına bakıldığında onlara gösterilen görsellerin bile nasıl görüş ve algılarını değiştirdiğini, yönlendirdiğini açık bir şekilde görülmektedir.

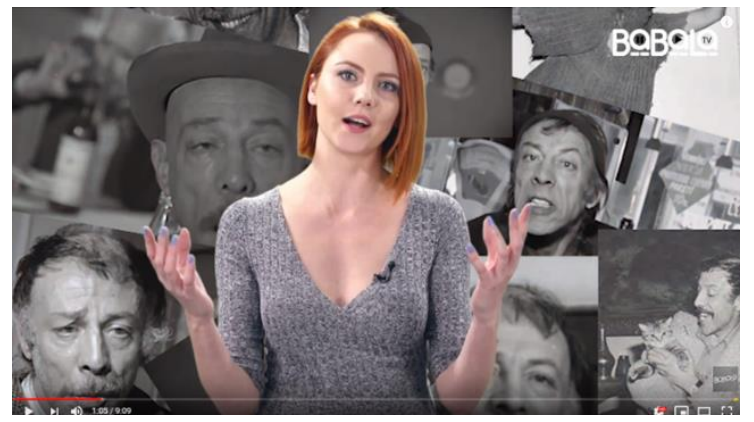

Görsel 7: Pelin Ongun, Youtuber, Sunucu

Kaynak: https://www.youtube.com/results?search_query=babala+pelin+olgun

Tablo 8: Öğretmen Adaylarının "Babala/Vibio" Görseline Yönelik Erkek ve Kadın İmajları

\begin{tabular}{ll}
\hline Bakış Açısı & Frekans \\
\hline Kadın videolarda dikkat çekmek için vardır & 3 \\
Çekici kadın imajı ahlaki değerlere uygun değildir & 2 \\
Kadının konuşma becerileri erkeklerden gelişmiştir & 1 \\
\hline Toplam & $\mathbf{6}$ \\
\hline
\end{tabular}

Öğretmen adaylarının gösterilen youtuber görsellerine ilişkin vermiş oldukları cevaplardan 16 katılımcı içerisinden 3 kişi kadının videolarda sunuculuk rollerinin verilmesinin çekici ve dikkat çekici olmasıdır cevabını vermiş̧tir. Katılımcılardan 2 kişi yöneltilen sorulara kadının sunucu rolünde bakımlı ve çekici olmasını ahlaki değerler bakımından uygun olmadığı cevabını vermiştir. Katılımcılardan 1 kişi kadının konuşma beceresinin yüksek olmasından dolayı sunuculuk gibi rollerde yer alması gerektiği cevabını vermiştir. Öğretmen adaylarının görüşleri şu şekildedir: "Görsellerde kadın imajında kadınların konuşma konusunda erkeklerden daha iyi olmaları sunuculuk gibi rolleri kadına kazandırmıştır (Selim)". "Görselde kadın imajı dikkat çekmek için kullanılmıştır (Aykut)". "Görseldeki kadın güzel bakımlı ve dikkat çekicidir. Güzel bir kadın 
olmasaydı zaten sunuculuk yapamazdı (Damla)". Öğretmen adaylarına sorulan sorulara ilişkin alınan cevaplarda öğretmen adaylarının çoğunluğunun kadına yönelik algılarında çekicilik, güzellik ve bakım kavramlarını kadın ile özdeşleştirmişlerdir. Bu durum öğretmen adaylarının kadına yönelik belli bir yönde bir imaj oluşturmalarına yol açmıştır.

\section{Görüşme Formu}

Sosyal Medyada Kadın ve Erkek İmajlarına İlişkin Algıya Yönelik Yapılandırılmış

Öğretmen adaylarının "Youtuberlar Üzerinden Kadın ve Erkek İmajları Hakkında Ne Düşünüyorsun Çalışma Yaprağı" içerisinde öğretmen adaylarına yöneltilen soruların cevaplarına ilişkin görüşlerin frekansları aşağıdaki tabloda verilmiştir.

Tablo 9: Öğretmen Adaylarının “Kadın ve Erkek Youtuberları Ne Sıklıkla İzliyorsunuz?" Sorusuna Yönelik Görüșleri

\begin{tabular}{ll}
\hline Bakıs Açısı & Frekans \\
\hline İzliyorum çünkü zaman geçirmek için & 5 \\
İzlemiyorum çünkü faydalı değiller & 5 \\
Nadiren izliyorum çünkü saçma & 6 \\
\hline Toplam & $\mathbf{1 6}$ \\
\hline
\end{tabular}

Öğretmen adaylarının gösterilen youtuber görsellerine ilişkin yöneltilen çalıma yaprağındaki cevaplardan 16 katılımcı içerisinden 5 kişi zamanımı geçirmek için youtuberları izliyorum cevabını vermiştir. Katılımcılardan 5 kişi yöneltilen soruya izlemiyorum çünkü video içerikleri faydalı değil hepsi saçma ve zaman kaybı olduğu cevabını vermiş̧ir. Katılımcılardan 6 kişi youtuberları nadiren takip ettiklerini özelikle youtuberlar için zaman ayırmadıklarını denk gelirse izledikleri cevabını vermiştir. Öğretmen adaylarının görüşleri şu şekildedir: "İzlemiyorum çünkü internetim yok olsaydı izlerdim (Vedat). "Bazen izliyorum canım çok sıkılırsa saçma diziler izlemek yerine daha az zaman harcayacağım youtube videolarını izlemeyi tercih ediyorum (Mehmet)". "İzliyorum çünkü hayatımda bazen bana çok faydalı olabiliyorlar (Damla)". Öğretmen adaylarına sorulan sorulara ilişkin alınan cevaplarda öğretmen adaylarının çoğunluğunun kadın erkek ayırt etmeden youtuberları nadiren izlediklerini belirtmiştir. Öğretmen adayları youtuberları izlemelerinin sebebini ise zaman geçirmek, boş vakitlerin değerlendirmek için olduğu görüşündedir. $\mathrm{Bu}$ durum öğretmen adaylarının boş zamanlarında ne yapacaklarını bilemeyip boş zamanlarını değerlendiremedikleri sonucu çıkarılabilir.

Öğretmen adaylarının "Youtuberlar Üzerinden Kadın ve Erkek İmajları Hakkında Ne Düşünüyorsun Çalışma Yaprağı" içerisinde öğretmen adaylarına yöneltilen "Kadın ve erkek Youtuberlar ne tür bir imaj sergilemektedir? Sergilemiş oldukları imajlar cinsiyete göre farklılık gösteriyor mu?" sorusunun cevaplarına ilişkin görüşlerin frekansları aşağıdaki tabloda verilmiştir.

Tablo 10: Öğretmen Adaylarının "Kadın ve Erkek Youtuberlar Ne Tür Bir İmaj Sergilemektedir? Sergilemiş Oldukları İmajlar Cinsiyete Göre Farklılık Gösteriyor Mu?” Sorusuna Yönelik Görüşleri

\begin{tabular}{ll}
\hline Bakıs Açısı & Frekans \\
\hline Kadın olarak öne çıkan imajlar; & \\
Makyaj & 4 \\
Çekicilik ve güzellik & 3 \\
Yemek yapan & 4 \\
Erkek olarak öne çıkan imajlar; & 4 \\
Güçlü & 3 \\
Bilim ile ilgilenen & 3 \\
Özgür & $\mathbf{1 6}$ \\
\hline Toplam & \\
\hline
\end{tabular}


Öğretmen adaylarının gösterilen youtuber görsellerine ilişkin yöneltilen çalışma yaprağındaki cevaplardan 16 katılımcı içerisinden 4 kişi kadın imajında öne çıkan özelliğin makyaj yapmak olduğu cevabını vermiştir. Katılımcılardan 3 kişi kadın imajında çekicilik ve güzelliğin ön planda olduğu cevabını vermiştir. Katılımcılardan 4 kişi kadın imajında öne çıkan özelliğin yemek yapmak olduğu yönünde olduğunu ifade etmişlerdir. Öğretmen adaylarının erkek imajına yönelik 4 kişi erkeğin güçlü olduğu, 3 kişi erkeğin bilim ve araştırma konularıyla ilgilendiği, 3 kişi ise erkek imajında özgür olduğuna yönelik özelliklerin ön plana çıktığı doğrultusunda cevaplar vermişlerdir. Öğretmen adaylarının görüşleri şu şekildedir: "Tüm kadınlar makyaj yapar ve dikkat çekmeye çalışır, erkek ise daha çok zekâsıyla öne çıkar (Mazlum). "Kadın yemek konusunda erkeklerden çok daha başarılıdır o yüzden kadın hep yemek yapar, erkke güçlüdür bu yüzden erkek spor yapar, araba sürer, her şeyin üstesinden gücü ile gelir (Arda)". "Kdın güzelliği ile dikkat çeker dikkat çekmek içinde makyaj yapar kendine bakar, erkek ise daha özgür olduğu için birçok şey yapabilir (Damla)". Öğretmen adaylarına sorulan sorulara ilişkin alınan cevaplarda öğretmen adaylarının çoğunluğunun kadını makyaj, yemek ve dikkat çeken gibi kavramlarla öne çıkarırken erkeği gücü, zekâsı ve özgür olması ile öne çıkarmıştır. Öğretmen adaylarının algılayış biçimleri onlara gösterilen bir görselle bile nasıl değiştiğini görülebilmektedir. Sosyal medyada binlerce görsellere maruz kalındığı düşünüldügünde bu etkinin gücünü daha da arttırdığ 1 tahmin edinilebilir.

Öğretmen adaylarının "Youtuberlar Üzerinden Kadın ve Erkek İmajları Hakkında Ne Düşünüyorsun Çalışma Yaprağı" içerisinde öğretmen adaylarına yöneltilen "Kadın ve erkek youtuberların oluşturmuş oldukları imajları nasıl görüyorsun?" sorusunun cevaplarına ilişkin görüşlerin frekansları aşağıdaki tabloda verilmiştir.

Tablo 11: Öğretmen Adaylarının "Kadın ve Erkek Youtuberların Oluşturmuş Oldukları İmajları Nasıl Görüyorsun?" Sorusuna Yönelik Görüşleri

\begin{tabular}{lc}
\hline Bakış AçıSı & Frekans \\
\hline Kadın imajı; & \\
Çekicilik ve güzellik & 3 \\
Konuşmayı seven & 2 \\
Erkek imajı; & 3 \\
Ağır başlılık & 3 \\
Özgür olan & $\mathbf{1 1}$ \\
\hline Toplam & 3 \\
\hline
\end{tabular}

Öğretmen adaylarının gösterilen youtuber görsellerine ilişkin vermiş oldukları cevaplardan 16 katılımcı içerisinden 3 kişi kadın imajında çekicilik ve güzellik kavramlarının göze çarptığı cevabını vermiştir. Katılımcılardan 2 kişi yöneltilen sorulara kadının konuşmayı seven bir imajda olduğunu bu yüzden kadın youtuberların çok konuştuğu cevabını vermiştir. Katılımcılardan 3 kişi erkek youtuberların kadın youtuberlara göre daha ağırbaşlı davrandıkları cevabını verirken, 3 kişide erkek imajında özgürlük kavramının ön planda olduğu bu yüzden erkek youtuberların içeriklerinin çeşitlilik bakımından kadın youtuberlardan daha fazla olduğu cevabını vermiş̧tir. Öğretmen adaylarının görüşleri şu şekildedir: "Kadın erkeğe göre toplumun sadece bir köşesinde kalan erkek ise yaşamın her yerine hâkim çünkü erkek kadından daha özgür (Selim)". "Erkek youtuberlar kadın youtuberlara göre daha öz ve net konuşur bu yüzden erkekler youtuberlık konusunda daha çok kişi tarafından izlenir (Aykut)". "Kadınlar hep aynı konularda videolar çekiyor bu videolar genelde makyaj, moda bakım falan (Seda)". Bu durum öğretmen adaylarının kadın ve erkekleri kategorize ettiklerine ve belli kalıplar içerisine koymalarına yol açmıştır.

Öğretmen adaylarının "Youtuberlar Üzerinden Kadın ve Erkek İmajları Hakkında Ne Düşünüyorsun Çalışma Yaprağı" içerisinde öğretmen adaylarına yöneltilen "Günlük hayatta çizdiğimiz imajlar kadın ve erkek youtuberların çizdiği imajla benzerlik taşıyor mu?" sorusunun cevaplarına ilişkin görüşlerin frekansları aşağıdaki tabloda verilmiştir. 
Tablo 12: Öğretmen Adaylarının "Günlük Hayatta Çizdiğimiz İmajlar Kadın ve Erkek Youtuberların Çizdiği İmajla Benzerlik Taşıyor Mu?” Sorusuna Yönelik Görüşleri

\begin{tabular}{ll}
\hline Bakış Açıs & Frekans \\
\hline Evet çünü onlara özeniyorum & 1 \\
Hayır çünkü beni etkilemiyorlar & 12 \\
Kısmen bazı yönlerden etkileniyorum & 2 \\
\hline Toplam & $\mathbf{1 5}$ \\
\hline
\end{tabular}

Öğretmen adaylarının gösterilen youtuber görsellerine ilişkin yöneltilen çalıma yaprağındaki cevaplardan 16 katılımcı içerisinden 1 kişi youtuberlardan etkilendiğini ve bu etkinin günlük yaşamına yansıdığı cevabını vermiştir. Katılımcılardan 12 kişi yöneltilen soruya youtuberların kendilerini etkilemedikleri ve günlük yaşamlarında herhangi bir yansımanın olmadığı cevabını vermiştir. Katılımcılardan 2 kişi ise youtuberlardan bazı konularda etkilendikleri cevabını vermiştir. Öğretmen adaylarının görüşleri şu şekildedir: "Hayır etkilenmem çünkü ahlaki yönden davranışlarını uygun bulmuyorum (Selim). "Bazen etkilendiğimi düşünüyorum mesela konuşma tarzım bazen damla bilicinkine benziyor. Fakat bunu istemsiz yapıyorum (Ayşe)". Öğretmen adaylarına sorulan sorulara ilişkin alınan cevaplarda öğretmen adaylarının çoğunluğunun youtuberlardan etkilenmedikleri cevabı alınmıştır. $\mathrm{Bu}$ durum öğretmen adaylarının izlemiş oldukları videolardaki imajların belli bir etki söz konusu olsa da youtubun çizdiği kadın ve erkek imajlarındaki davranışların öğretmen adaylarının yaşamına etki edecek kadar öğretmen adaylarıi etkilemediği sonucu çıkarılabilir.

Öğretmen adaylarının "Youtuberlar Üzerinden Kadın ve Erkek İmajları Hakkında Ne Düşünüyorsun Çalışma Yaprăğ" içerisinde öğretmen adaylarına yöneltilen "Youtuberların giyim tarzları, konuşma şekilleri ve yaşam tarzlarını örnek alıyor musunuz? Ya da sizi etkiliyor mu?" sorusunun cevaplarına ilişkin görüşlerin frekansları aşağıdaki tabloda verilmiştir.

Tablo 13: Öğretmen Adaylarının "Youtuberların Giyim Tarzları, Konuşma Şekilleri ve Yaşam Tarzlarını Örnek Alıyor Musunuz? Ya da Sizi Etkiliyor Mu?" Sorusuna Yönelik Görüşleri

\begin{tabular}{ll}
\hline Bakış Açısı & Frekans \\
\hline Evet etkiliyor çünkü yaşam tarzları çok havalı & 2 \\
Hayır etkilemiyor yaşam tarzları topluma uygun değil & 12 \\
Kısmen etkiliyor & 2 \\
\hline Toplam & $\mathbf{1 6}$ \\
\hline
\end{tabular}

Öğretmen adaylarının gösterilen youtuber görsellerine ilişkin vermiş oldukları cevaplardan 16 katılımcı içerisinden 2 kişi youtuberların yaşam tarzından etkilendiği çünkü çok havalı oldukları cevabını vermiştir. Katılımcılardan 12 kişi yöneltilen soruya youtuberların yaşam tarzlarının kendilerini etkilemediklerini çünkü toplumun ahlak değerlerine uygun bir yaşam sergilemedikleri cevabını vermiştir. Katılımcılardan 2 kişi ise nedeni hakkında açıklama yapmadan youtuberlardan kısmen etkilendikleri cevabını vermiştir. Öğretmen adaylarının görüşleri şu şekildedir: "Açıklayıcı olmaları yaş gruplarına göre davranış ve konuşmalarına dikkat etmeleri gerekir (Selim)". "Topluma faydalı konular üzerinde yoğunlaşmaları bunu yaparken de toplumun ahlaki görüşü ile paralel düşünmeleri gerekir (Aykut)". "Etkileyici havalı bir yaşamları olduğu için onlar gibi yaşamak isterdim (Damla)". Öğretmen adaylarına sorulan sorulara ilişkin alınan cevaplarda öğretmen adaylarının çoğunluğunun toplumun ahlaki değerlerini önemsedikleri bu değerlere göre hareket edilmesi gerektiği yönde cevaplar vermişleridir. $\mathrm{Bu}$ durum öğretmen adaylarının toplumun kararlarını önemsedikleri gelenek ve göreneklerini hala kaybetmedikleri, ayrıca youtube'un öğretmen adaylarının kadın ve erkeğe yönelik belli yönde toplumun ahlaki değerlerine uygun olmayan bir imaj oluşturmalarına yol açmıştır. 
Öğretmen adaylarının "Youtuberlar Üzerinden Kadın ve Erkek İmajları Hakkında Ne Düşünüyorsun Çalışma Yaprağı" içerisinde öğretmen adaylarına yöneltilen "Size göre bir kadın veya erkek youtuber nasıl özellikler taşımalı?” sorusunun cevaplarına ilişkin görüşlerin frekansları aşağıdaki tabloda verilmiştir.

Tablo 14: Öğretmen Adaylarının "Size Göre Bir Kadın veya Erkek Youtuber Nasıl Özellikler Taşımalı?" Sorusuna Yönelik Görüşleri

\begin{tabular}{ll}
\hline Bakış Açısı & Frekans \\
\hline Kadın imajı için; & 5 \\
Cinsyet olarak video içeriklerinin değinmemeli & 4 \\
Ahlaki yönden daha dikkatli davranmalı & 5 \\
Topluma faydalı konular seçmeli & \\
Erkek imajı için; & 2 \\
Bakımlı olmalı & $\mathbf{1 6}$ \\
\hline Toplam & Şa \\
\hline
\end{tabular}

Öğretmen adaylarının gösterilen youtuber görsellerine ilişkin yöneltilen çalıma yaprağındaki cevaplardan 16 katılımcı içerisinden 5 kişi cinsiyet olarak video içeriklerinin değişmemesi gerektiği kadın isterse erkeğinde yapabileceği her şeyi yapabileceği cevabını vermiştir. Katılımcılardan 4 kişi yöneltilen soruya kadın youtuberların gerek davranış gerek giyim gerekse konuşma üsluplarında ahlaki değerlere uygun davranmaları gerektiği cevabını vermiştir. Katılımcılardan 5 kişi youtuber video içeriklerinin topluma faydalı konular üzerine seçilmesi gerektiği cevabını verirken 2 kişi erkeklerin bakımsız olduğunu erkeklerin de kadınlar kadar kendilerine bakmaları gerektiği cevabını vermiştir. Öğretmen adaylarının görüşleri şu şekildedir: "Youtuber içeriklerinde erkeklerin bakımsızlığı beni çok rahatsız ediyor yabancı youtuberlara baktığımda onlar çok bakımlılar Türk youtuberlarında bakımlı olması gerekli (Aysel). "Youtuberların video içerikleri faydalı konular üzerine değil toplum bu videolardan faydalanmalı faydalı konular seçilmeli (Aykut)". "Video içerikleri kızlarda da erkeklerde de aynı olabilmeli değişmemeli (Damla)". Öğretmen adaylarına sorulan sorulara ilişkin alınan cevaplarda öğretmen adaylarının youtuber video içeriklerini faydalı bulmadıkları ve içeriklerin cinsiyete göre değişmemesi yönünde cevaplar vermişleri. Ögretmen adaylarının vermiş oldukları cevaplardan öğretmen adaylarının cinsiyetlerine yönelik bir kısıtlama getirilmesini doğru bulmadıkları yaklaşımı çıkarılabilir.

Tablo 15: Öğretmen Adaylarının "Toplumsal Cinsiyet Rolleri Kadın ve Erkek Youtuberlar Üzerinde Bir Etkisi Var Mi? Youtuberlar Bu Rollere Uygun Hareket Ediyorlar Mi?" Sorusuna Yönelik Görüşleri

\begin{tabular}{l|ll}
\hline Bakış Açısı & & Frekans \\
\hline & Toplum tarafindan dışlanır & 3 \\
Çünkü... & Tolum tarafından olumsuz tepki alır & 2 \\
& Erkeğin yaptığı her şeyi kadın yapamaz & 2 \\
& & \\
\hline Toplam & & $\mathbf{7}$ \\
\hline
\end{tabular}

Öğretmen adaylarının gösterilen youtuber görsellerine ilişkin yöneltilen çalışma yaprağındaki cevaplardan 16 katılımcı içerisinden 3 kişi youtuberların toplumsal cinsiyet rollerine uygun davrandıkları uygun davranılmadığı taktirde toplum tarafindan dışlanacağı cevabını vermiştir. Katılımcilardan 2 kişi yöneltilen soruya youtuberların toplumsal cinsiyet rollerine göre hareket ettikleri bunun sebebinin tolumdan olumsu tepki almak tan korkmaları olduğu cevabını 
vermiştir. Katılımcılardan 2 kişi ise youtuberların cinsiyet rollerine uygun hareket etmek zorunda oldukları çünkü erkeğin güçlü kadının ise güçsüz olmasından dolayı erkeğin yaptığı herşeyi kadının yapamayacağı cevabını vermiştir. Öğretmen adaylarınıngörüşleri şu şekildedir: "Eğer topluma göre hareket etmezlerse toplumdan kötü yönde tepki alırlar ve kimse onları izlemez (Selim)". "Erkeğin yaptığı herşeyi kadın yapamaz toplumda böyle düşünür o yüden kadının yaptığı şeyler ayrı erkeğin yaptığ 1 şeyler farklı olmalı (Ahmet)". "Topluma uygun davranılmazsa toplum bizi istemez dişlar (Duygu)". Öğretmen adaylarına sorulan sorulara ilişkin alınan cevaplarda öğretmen adaylarının çoğunluğunun youtuberların toplum cinsiyet rollerine uygun hareket etmeli gerektiği yönünde cevaplar vermiş. Bu durum toplumun insan üzerindeki etkisinin gözle görünür bir yansımasıdır.

Tablo 16: Öğretmen Adaylarının "Kadın ve Erkek Youtuberların İçerikleri Cinsiyet Açısından Farkl11ık Gösteriyor Mu?" Farkl1lık Gösteriyorsa Bu Neden Olabilir?” Sorusuna Yönelik Görüşleri

\begin{tabular}{ll}
\hline Bakış Açısı & Frekans \\
\hline Kadın video içerikleri; & \\
Yemek & 2 \\
Makyaj & 5 \\
Çekicilik & 2 \\
Erkek video içerikleri; & \\
Spor & 2 \\
Bilim & 2 \\
Eğlence & 3 \\
\hline Toplam & $\mathbf{1 6}$ \\
\hline
\end{tabular}

Öğretmen adaylarının gösterilen youtuber görsellerine ilişkin yöneltilen çalıma yaprağındaki cevaplardan 16 katılımcı içerisinden 9 kişi kadın youtuber içeriklerine ilişkin yemek, makyaj ve çekicilik cevabını vermiştir. Katılımcılardan 7 kişi yöneltilen soruya erkek video içeriklerine ilişkin spor, bilim ve eğlence katagorileri cevabını vermiştir. Öğretmen adaylarınıngörüşleri şu şekildedir: "Youtube'a girdiğimde hep karşıma kadın youtuberların makyaj videoları çıkmakta farklı bir içeriğe kadın olarak rastlamadım (Selim)". "Evet ediyor çünkü erkeğin yaptığı herşeyi kadın yapamaz örneğin makyaj kadın yapar erkek yapamaz (Ahmet)". "Tabi ki gösteriyor özellikle bilim ve araştırmaya yönelik içerikler kadın youtuberlar da maalesef yok çünkü kadının ilgi alanında bilim ve araştırma yok (Damla)". Öğretmen adaylarına sorulan sorulara ilişkin alınan cevaplarda öğretmen adaylarının çoğunluğunun cinsiyet açısından video içeriklerinin farklılık gösterdiğini düşünmekte ve erkek ve kadına yönelik belli bir kalıplaşma olduğu sonucu çıkarılabilir.

Tablo 17: Öğretmen Adaylarının "İzlediğiniz veya Takip Ettiğini Youtuberların Görüntülerini ve Anlatmış Oldukları Konuları Ele Alan Bir Yazı Oluşturunuz?” Sorusuna Yönelik Görüsşleri

\begin{tabular}{|c|c|}
\hline Bakış Açısı & Frekans \\
\hline Magazin & 2 \\
\hline Makyaj & 3 \\
\hline Günlük yaşam ve eğlence & 5 \\
\hline Spor & 2 \\
\hline Bilim & 3 \\
\hline Toplam & 15 \\
\hline \multicolumn{2}{|c|}{$\begin{array}{l}\text { Öğretmen adaylarının gösterilen youtuber görsellerine ilişkin yöneltilen çalışma } \\
\text { yaprağındaki cevaplardan } 16 \text { katılımcı içerisinden } 2 \text { kişi izlemiş veya takip etmiş olduğu } \\
\text { youtuberların ele almış olduğu konunun magazin olduğu cevabını vermiştir. Katılımcılardan } 3 \text { kiş̧ } \\
\text { yöneltilen soruya makyaj cevabını vermiştir. Öğretmen adaylarından } 5 \text { kişi takip ettiği ve izlediğ } \\
\text { youtuberların günlük yaşam ve eğlence ile ilgili konular ele aldığı cevabını vermiştir. Öğretmen }\end{array}$} \\
\hline
\end{tabular}


adaylarından 2 kişi işlemiş veya takip ettği youtuberın spor içerikli konular ile ilgilendiği cevabını veririken 3 kişi bilim cevabını vermiştir. Öğretmen adaylarının görüşleri şu şekildedir: "İzlemiş olduğum youtuber genellikle eğlence içerikli videolar yapar (Selim)". "İzlediğim videolar bilimle ilgilidir (Ahmet)". "İzlediğim videolar genellikle makyaj ve tanıtım ile ilgili olmakla birlikte eğlence içerikli videolardır (Damla)". Öğretmen adaylarına sorulan sorulara ilişkin alınan cevaplarda öğretmen adaylarının çoğunluğunun eğlence ve günlük yaşamı ilgilendiren konulu videolar çeken youtuberlar olmuştur. Soruya genellikle erkek katılımcilar haber, spor, bilim, oyun gibi cevaplar verirken, kız öğretmen adayları günlük yaşam, magazin, makyaj gibi cevaplar vermişlerdir.

Tablo 18: Öğretmen Adaylarının "Takip Ettiğini Youtuber Var Mı? Varsa Kimi Takip Ediyorsunuz" Sorusuna Yönelik Görüşleri

\begin{tabular}{l|ll}
\hline & Bakış Açısı & Frekans \\
\cline { 2 - 3 } & Cüneyt Özdemir (Gazeteci) & 1 \\
& Uras Benlioğlu (Ürün tanıtımı) & 1 \\
& Barış Özcan & 2 \\
& Reymen (Eğlence) & 2 \\
\hline Yok & Çünkü ilgimi çekmiyor & 6 \\
\hline & Toplam & $\mathbf{1 3}$ \\
\hline
\end{tabular}

Öğretmen adaylarının gösterilen youtuber görsellerine ilişkin yöneltilen çalıma yaprağındaki cevaplardan 16 katılımcı içerisinden 1 kişi sunucu youtuber Cüneyt Özdemir cevabını vermiş̧ir. Katılımcılardan 1 kişi yöneltilen soruya ürün tanıtım videoları yapan youtuber Uras Benlioğlu cevabını vermiştir. Öğretmen adaylarından 2 kişi bilim sanat ve teknoloji alanlarında içerikleri bulunan youtuber Barış Özcan cevabını vermiştir. Öğretmen adaylarından 2 kişi eğlence içerikli videolar çeken Reymen cevabını verken 6 kişi de youtuberları ilgilerini çekmedikleri için takip etmedikleri cevabını vermiştir. Öğretmen adaylarına sorulan sorulara ilişkin alınan cevaplarda öğretmen adaylarının çeşitli alanlarla ilgilenen youtuberları takip ettiği, belli bir kısmınınsa ilgilerini çekmediği için youtuberları takip etmediği görülmektedir.

Tablo 19: Öğretmen Adaylarının "Youtube Kanalında En Çok İzlediğiniz İçerik Nedir?” Sorusuna Yönelik Görüşleri

\begin{tabular}{ll}
\hline Bakış Açısı & Frekans \\
\hline Bilim & 2 \\
Din & 2 \\
Eğlence & 5 \\
Müzik & 4 \\
Yemek & 3 \\
\hline Toplam & $\mathbf{1 6}$ \\
\hline
\end{tabular}

Öğretmen adaylarının gösterilen youtuber görsellerine ilişkin yöneltilen çalıma yaprağındaki cevaplardan 16 katılımcı içerisinden 2 kişi sunucu bilim alanıyla ilgili videolar izlediğini belirtirken 2 kişi yöneltilen soruya din cevabını vermiş̧ir. Öğretmen adaylarından 5 kişi eğlence alanıyla ilgili içerikleri bulunan youtuberları takip ettiği cevabını verirken 4 kişi müzik cevabını vermiştir. Öğretmen adaylarından 3 kişi ise yemek alanı ile ilgilenen youtuberları sıklıkla takip ettiği cevabını vermiştir. Öğretmen adaylarına sorulan sorulara ilişkin alınan cevaplarda eğlence alanın yoğun olarak yer aldığı daha sonra müzik alanın cevaplarda sıklıkla yer alması toplum olarak bilim ve din gibi alanlardan uzaklaşmış olduğumuzu gösterebilir. Görsel sanatlar öğretmen adaylarının sanat içerikli videolar izlememesi dikkat çekmektedir. 
Tablo 20: Öğretmen Adaylarının “Youtube Kanalında En Az İzlediğiniz İçerik Nedir?” Sorusuna Yönelik Görüşleri

\begin{tabular}{ll}
\hline Bakış AçıIsı & Frekans \\
\hline Yemek (Erkek) & 2 \\
Makyaj (Erkek) & 5 \\
Eğlence & 2 \\
Müzik & 4 \\
\hline Toplam & $\mathbf{1 3}$ \\
\hline
\end{tabular}

Öğretmen adaylarının gösterilen youtuber görsellerine ilişkin yöneltilen çalışma yaprağındaki cevaplardan 16 katılımcı içerisinden 2 erkek öğretmen adayı yemek içerikli videolarını izlemeyi tercih etmediğini 5 erkek öğretmen adayı yöneltilen soruya makyaj cevabını vermiştir. Öğretmen adaylarından 2 kişi eğlence alanıyla ilgili içerikleri bulunan youtuberları takip etmediği cevabını verirken 4 kişi müzik cevabını vermiştir. Öğretmen adaylarına sorulan sorulara ilişkin alınan cevaplarda erkek öğretmen adaylarının makyaj ve yemek cevabını vermesi erkek imajında, erkek yemekle ilgilenmez, erkek makyaj yapmaz gibi kalıp yönelimlere yol açmıştır.

\section{Tartışma ve sonuç}

Toplumsal cinsiyet hayatın her alanında yer alan yaşamımızın gerçeklerinden biridir. Toplumsal cinsiyet rollerini toplum kendi oluşturur ve bu oluşumun sürekliliğini sağlar. Toplumun oluşturmak ve devam ettirmek istediği bu roller insanlarda bir baskı yaratır. Çünkü burada toplumun insandan beklediği istekler ve beklentiler vardır. İnsanın yaşamına yön veren bu roller yaşamımızın içerisinde yer alırken bu durum yaşamın bir yansıması olarak sayılabilecek olan televizyon, sinema, reklam afişleri, internet gibi kitlelere ulaşan araçlarında içerisinde yer almaktadır. Kitle iletişim araçları insanların düşüncelerini değiştirebilir ve var olan düşünceyi yok edilmesini sağlayabilecek kadar güçlüdür. İşte bu yüzden kitle iletişim araçlarında toplumsal cinsiyet rolleri nasıl yer almakta insanlara bu konuda zarar verebilecek ya da yanlış olan bir durumun düzeltilip insan için yararlı hale getirmek önemlidir. Bu açıdan kitle iletişim araçları üzerinden cinsiyet rollerinin belirlenmesi ve tespiti amacıyla birçok araştırma yapılmıştır.

$\mathrm{Bu}$ araştırmadan elde edilen bulgulara bakıldığında, öğretmen adayları kadın imajını güzellik, kozmetik, ilgi ve dikkat çekicilik, dekolte, duygusal, kurnaz, öz güven sahibi gibi özelliklerle öne çıkarmışlardır. Ayrıca kadının ekonomide erkeğe göre daha büyük bir güç sahibi olduğunu vurgulayan öğretmen adayları, kadının kapitalist sektörde ilgi ve dikkat çekiciliğinden dolayı daha çok tercih edildiğini belirtmişlerdir. Erkek imajına yönelik düşüncelerinde ise kadın imajında kullanmış oldukları kavramların hiçbiri yer almadığını ve özgür, öfkeli, deli, cesaretli gibi özelliklerin öne çıktığı gözlemlenmiştir. Araştırmada tüm bu açılardan öğretmen adaylarının kültürel değerlere göre cinsiyetçi bir tavır içerisinde olduğu söylenebilir. Etiler ve Zengin'in (2015:137-146) çalışmasında da benzer bir sonuca ulaşmıştır. Kadınlar tarafından yaygın olarak izlenen gündüz kuşağı programlarında sağlık sorunları olarak ele alınan konularda cinsiyetçi bir tavır sergilendiğini kadına yönelik hastalıkların yalnızca bir kısmının ele alındığını erkeğe yönelik sağlık konularının daha çok önemsendiği ve programda daha çok yer verildiğini tespit etmiştir.

$\mathrm{Bu}$ araştırmanın bulgularına bakıldığında, kadın yemek yapar, makyaj yapar, güzel olmak ister çünkü tüm bu eylemeler kadına yöneliktir, kadın erkekler kadar özgür olamaz, erkek özgürdür, güçlüdür, erkek istediği gibi davranabilir ancak kadın istediği gibi davranamaz, kadın video içerikleri hep belli kalıplarda konular üzerinedir bu konular moda, bakım gibi konularla kısıtlıdır ancak erkek video içerikleri oldukça çeşitlidir çünkü erkeğin kısıtlayan bir durum olamaz gibi ifadeler yer almaktadır. İfadelerde cinsler arasında kesin çizgilerle bir ayrım söz konusu olup cinsler belli kalıplar içerisine itilmektedir. Benzer bir biçimde kitle iletişim aracı olarak televizyon reklamları ve müzik videolarını inceleyen Ersoy Çak (2010) çalışmasında, toplumsal örneklemelerin sergilendiği medya unsurları içerisinde kadına ve erkeğe tahsis edilmiş bazı görevler olduğu gözlemlenmiştir. Bu araştırmada toplumsal cinsiyet rolleri youtuber video 
görselleri üzerinden belirlenmeye çalışılmış ve sonuç olarak video görsellerine yönelik öğretmen adayların ifadelerinde kalıplaşmış cinsiyet rollerin yer aldığı gözlenmiştir.

$\mathrm{Bu}$ araştırmada yer alan bulgular incelendiğinde kadın öğretmen adayları tarafından kadın imajına yönelik ifadelerinde güzellik, kozmetik, ilgi ve dikkat çekicilik, dekolte, duygusal, kurnaz, öz güven sahibi, gibi kavramalardan bahsederken erkek imajında erkeğin kadın kadar dikkat çekmediği ifade edilmiştir. Bu duruma benzer bir sonuca ulaşan Yüksel (2006) çalışmasında genel olarak reklamların yerleşik cinsel rolleri nasıl yeniden üretmekte oldukları örneklerle açıklanmaktadır. Aynı bakış açısıyla, daha özel bir alan olarak, kamusal alanın önemli bir parçası olan otomobil reklamlarında mesajın cinsel rollerle nasıl ilişkilendirildikleri yine örnekler aracılığıyla betimlenmiştir. Betimlemelerde bu araştırmanın sonucuna benzer olarak kadının dikkat çekiciliği ve ilgi çekiciliğinin reklamlarda otomobil ile ilişkilendirilerek sunulması kadını belli kalıplara itiyor ve kadın imajına yönelik algıyı etkiliyor ve öğretmen adaylarının ifadelerini pekiştiriyor denebilir. Bu araştırmadaki bulgulara göre kadın birçok kitle iletişim aracın da olduğu gibi youtuber videolarında da kadın belli kalıplar içerisine hapsedilmeye çalışılmakta. Bulgular gösteriyor ki öğretmen adayları tarafından kadın yemek yapar, ev işleriyle ilgilenir, kadının sokakta yeri yoktur, kadın hal ve hareketlerinde erkekler kadar özgür davranamaz, kadın zekâ ve bilim kavramları içerisinde yer alamaz düşüncesi savunulmakta ve cinsiyetçi davranış benimsenmektedir. $\mathrm{Bu}$ araştırmanın sonuçlarına benzer sonuçlara ulaşan Dumanlı (2011) toplumsal cinsiyet rollerinin sunumunda kitle iletişim araçları içerisinde televizyonun yadsınamaz bir yeri olduğunun altını çizerek reklamlarda kadına yönelik toplumsal cinsiyet rollerinin nasıl sunulduğunu açıklamak amacıyla yapmış olduğu araştırmasında yemek çocuk bakımı, ev temizliği, güzellik, kozmetik gibi reklam sektörlerinde kadının sıkça yer aldığı ve bu durumun sürekli tekrarlandığı sonucunu tespit etmiştir. Dumanlının araştırmasının bulgularında da kadın belli kalıplar içerisine alınmaya çalışılmıştır.

$\mathrm{Bu}$ araştırmada, öğretmen adaylarında cinsiyetçi yaklaşım sergiledikleri, youtuber video görselleri üzerinden tespit edilmiş olup kadına belli roller ve sorumluluklar verilmesi gerektiği erkek ise herhangi bir sorumluluk veya rol üstlenmemesi gerektiği görüşü tespit edilmiştir. Benzer bir biçimde Kalan (2010) araştırmasında çocukların cinsel kimlik rollerine ilişkin bilgileri öncelikle iletişim kurduğu ailesinden, daha sonra ise kitle iletişim araçlarından almakta olduğunu belirterek, çocukları tüketici konuma alan reklamlardan birisi olan Kinder reklamında çocuğun toplumsal cinsiyet rolleri bakımından nasıl bir konumda yer aldığı araştırılmıştır. Araştırma sonucunda ise kız ve erkek çocukların toplumsal cinsiyet kalıp yargılarını yansıtan rol ve davranış biçimlerine uygun kurgulandıkları görülmüştür. Bu araştırmanın bulgularına göre kadın ve erkeğe eşit haklar verilmemiş erkeğin sahip olduğu birçok haktan kadın yoksun bırakan, üstlenilen sorumluluklar konusunda kadına adaletsiz davranan bir anlayış tespit edilmiştir. Konu ile alakalı Yeşil ve Yıldırım (2019) cinsiyet rollerinin öğretilmesinde ve aktarılmasında aile, eğitim kurumları ve kitle iletişim araçları olduğunun altı çizilen araştırmasında kitle iletişim aracı olarak TV kanallarında yayınlanan evlilik programlarını incelenmiş ve cinsiyet rolleri ve sorumlulukların cinsler arasında eşit ve benzer olup olmadığı anlaşılmaya çalışılmıştır. Araştırma sonuçlarında incelenen söylemlerde yapılan araştırma sonuçlarına benzer olarak toplumsal cinsiyet rolleri ve sorumluluklarında cinslere eşit ve benzer roller vermediği tespit edilmiştir. Bu araştırmanın sonuçlarında cinsler arasındaki eşitsizliğe dikkat çekebilecek reklamların olduğunu tespit eden Çilingir (2019) kadına yönelik toplumsal cinsiyet stereotipilerinin "Kadınlar Günü" reklamları özelinde incelemiş ve söz konusu algılara yönelik bir değişim olup olmadığını ortaya koymaya çalışmıştır. 31 reklam filmine yer verilen araştırmanın sonucunda reklamda dış ses ve konuşmacı karakterlerin cinsiyeti ile kadın karakterlerin yaşı dışındaki araştırma bulgularına göre kadınlar büyük ölçüde yerleşik toplumsal cinsiyet stereotipilerindeki geleneksel rollerin dişında tasvir edilmektedir. Bu açıdan bakıldığında araştırmada söz konusu reklamların toplumsal cinsiyet eşitliğine hizmet ettiği sonucuna varılmıştır. 
$\mathrm{Bu}$ araştırmada kadına yüklenen sorumluluklar ev işlerini yapmak, güzel olmak, dikkat çekici olmak, makyaj yapmak, özgür davranışlar sergilememek ve daima bu konuda dikkatli davranmak, gece ve eğlence hayatı olmamak vb. şeklindedir. Benzer bulgulara Niloya adlı çizgi filminden ulaşan Yağan Güder ve diğerlerinin (2017) yapmış olduğu araştırmada Niloya adlı çizgi filmin 50 bölümünü izlemiş ve verileri içerik analiz yolu ile analiz etmiştir. Araştırma sonucunda çizgi filmde toplumsal cinsiye rollerine uygun davranış ve görünümler belirlenmiş olup çizgi filmin toplumsal cinsiyet kalıp yargılarının üretilmesine katkı sağladığı tespit edilmiştir. Çizgi filmde gösterilen yemek yapma, ev temizleme, çocuğa bakma gibi işlerle hep annenin ilgilendiği araba sürme bahçe işleri ve hayvanlarla ilgilenme davranışlarının ise baba ve dedenin üstlendiği tespit edilmiştir. Ayrıca çizgi filim karakterlerinin giysi renkleri yine cinsiyete göre ayrılmakta pembe ve mor renkleri kız karakterlere, mavi sarı ve yeşil renkleri ise erkek karakterlere giydirildiği gözlemlenmiştir.

$\mathrm{Bu}$ araştırmada erkek ve kız öğretmen adaylarının toplumsal cinsiyet rollerine uygun bir anlayış benimsedikleri ve geleneksel bir bakış açısında oldukları tespit edilmiştir. Benzer sonuçlara ulaşan Velikuluçay ve diğerleri (2007) araştırmasında üniversite son sınıf öğretmen adaylarının toplumsal cinsiyet rollerine ilişkin bakış açıları cinsiyetlerine göre çalışma yaşamı, toplumsal yaşam, evlilik yaşamı ve aile yaşamı ile ilgili yönlendirilen önermelere yapılan yorumlar üzerinden tespit edilmeye çalışılmış, elde edilen bulgulara göre erkek öğretmen adaylarının kız öğretmen adaylara göre daha geleneksel bir bakış açısına sahip oldukları, ancak evlilik yaşamı ile ilgili önermeleri değerlendirildiğinde; kız öğretmen adayların erkek öğretmen adaylara göre daha geleneksel bir bakış açısına sahip oldukları tespit edilmiştir.

$\mathrm{Bu}$ araştırmadaki bulguların sonucunda birçok konuda özellikle bilim, zekâ, özgürlük gibi konularda erkeğin egemen olduğu ve genel anlamda erkek egemen bir bakış açısının öğretmen adaylarca benimsendiği, kadının birçok konuda geri plana atıldığı tespit edilmiştir. Benzer sonuçlar ile karşılaşan Mora (2005) kitle iletişim araçları üzerinden yeniden üretilmeye çalışılan cinsiyetçilik ve topluma bu durumun nasıl yansıdığıyla ilgili yapmış olduğu araştırmasında kapitalist üretimin toplumsal değer yargılarına uygun kadın ve erkek imgesine göre üretildiğini, ancak kitle iletişim araçları var olan feodal değerleri sorgulamada kabul ederek erkek egemen ideolojinin sürekliliğine katkı sağladığını tespit etmiştir. Mola toplumun kadın imajı üzerinden süre getirdiği kutsal anne ve eş değerinin var olduğunu bu açıdan aslında toplumumuzun kadına değer verdiğini belirtirken araştırmasında kitle iletişim araçlarının bu değeri yok saydığını kadını aşağılayarak değersiz kıldığını tespit etmiştir.

$\mathrm{Bu}$ araştırmanın bulguları dikkate alınarak varılan sonuçlarda kadın imajına ilişkin akla gelen ilk kavramların başında dikkat çekicilik, dekolte, güzellik, cezbedici, ilgi çekici gibi kelimeler olmuştur. İfadelerde özellikle bu kavramlar öğretmen adayları tarafindan ön plana çıkarılmıştır. $\mathrm{Bu}$ araştırmanın bulgularına benzer Akmeşe ve Deniz (2015:311-326) ise kitle iletişim araçları üzerinden kadının konumunu, yeni medya ve geleneksel medya arasında kadının temsil biçimlerini değerlendirmek amaçlı yapmış olduğu araştırmasında, kadınların iş hayatı, başarıları ve benzeri olumlu haberlere çok az ya da hiç yer verilmediği görülmüştür. Kadınlar için anne, eş, sevgili, gelin, kuma, bayan, prenses, yabancı uyruklu, hanım vb. sıfatların kullanıldığı görülmektedir. Kullanılan sıfatlara baktığımızda kadını yüceltici başarısını, kişiliğini olumlayıcı sıfatlara rastlanmazken, genellikle kadının başka bir kişi üzerinden tanımlanmasını sağlayan (anne, eş, sevgili, kayınvalide vb.) sıfatlar ile kadının fiziksel özellikleri ve cinselliğini (güzellik kraliçesi, prenses, cazibe, taş bebek vs.) ön plana çıkaran sıfatların kullanıldığı görülmektedir. Haberlerde kullanılan görsel imge ve fotoğraflar incelendiğinde mağduriyet haberlerinde kadını ağlarken, elini başına koymuş vaziyette, çaresizlik içerisinde gösteren karelerin, cinsellik, fiziksel özellik vb. durumları ön plana çıkaran haberlerde ise kadının bedenini, dekoltesini, cinselliğini ön plana çıkaran karelerin tercih edildiği görülmektedir. 
$\mathrm{Bu}$ araştırmanın bulgularına göre kadın youtuber' ların video içerikleri arasında bilim, teknoloji, sanat gibi konuların yerine makyaj, yemek, kişisel bakım video içeriklerinin yer alması gerektiği öğretmen adayları tarafından ifade edilmiştir. Benzer bir konu ile ilgili Boylu ve diğerleri (2016) araştırmalarında geleneksel toplumsal cinsiyetçi iş bölümü çerçevesinde ortaya çıkan kalıp yargılar doğrultusunda teknolojinin üretim süreci içerisinde kadınların erkeklere oranla daha az sayıda bulunduğu ve erkeklerin bu alanda temel aktör rolünde yer aldığını tespit edilmiştir. Ayrıca ev i işleri kadına yöneliktir görüşü ve bu görüş içerisinde geliştirilmiş teknolojiler cinsiyetçi bir tavır takılarak bu konudaki sorumluluğu kadına bıraktığ 1 tespit edilmiştir. Elgün ve Alemdar (2017:1054-1067) ise iletişim fakültesi öğretmen adaylarının toplumsal cinsiyet rollerine ilişkin tutumlarının ve tutumlarda farklılaşmaya yol açabilecek çeşitli değişkenler ile demografik faktörlerin neler olduğunun ortaya konması ve aynı zamanda üniversite eğitiminin tutum farklılığına yol açıp açmadığının merak ederek 1. ve 4. sınıfların çalışma grubu olarak seçildiği araştırmanın bulgularına göre; ölçek içinde yer alan 5 boyuttan ilki olan kadın cinsiyet rolü açısından öğretmen adaylarının geleneksel ve eşitlikçi tutum yapısı açısından ortada bir değer aldıkları gözlenmiştir. Diğer dört boyutta ise bu araştırmanın sonucuna benzer evlilikte geleneksel, eşitlikçi, erkek eşitlikçi tutum yapısı gözlenmiştir. $\mathrm{Bu}$ araştırmanın sonucunda öğretmen adaylarının ifadelerinde ataerkil toplumun yansımaları tespit edilmiştir. Benzer sonuçlara ulaşan Cangöz'ün (2013) ele almış olduğu araştırmasında ise iletişim fakültesi öğretmen adaylarına toplumsal cinsiyet farklılığ 1 ve cinsiyetçi şiddet konusu tartışmaya açılmış tartışmanın sonucunda gazeteci adayların bilgi yetersizliği ve ataerkil toplumun norm ve ilkelerini tekrarlayan yanttlar araştırmacı tarafından tespit edilmiştir.

\section{Kaynakça}

Akmeşe Z., Deniz K. (2015). "Kadına Yönelik Cinsiyetçi Söylemin İnternet Haber Portallarında Yer Alma Biçimleri”. Uşak Üniversitesi Sosyal Bilimler Dergisi, 8(1): 311-326, https://doi.org/10.12780/uusbd.45190

Aksoy, N. (2006). Toplumsal Cinsiyete Dayalı Bütçeleme ve Kadının Statüsü Genel Müdürlüğünün Rolü. Ankara: T.C. Başbakanlık Kadının Statüsü Genel Müdürlüğü.

Aydiner Boylu, A., Ayan, H., Bilgin, İ. (2016). "Toplumsal Cinsiyet ve Ev Teknolojilerinin Kullanımına Etkisi". Insan ve Toplum Bilimleri Araştırmaları Dergisi, 5(4): 955-965, https://doi.org/10.15869/itobiad.35691

Barnard, M. (2002). Sanat Tasarım ve Görsel Kültür (Çev: Güliz Korkmaz), Ankara: Ütopya Yayınları.

Cangöz, D. (2014). "İletişim Fakültesi Öğrencilerinin Toplumsal Cinsiyet Farkındalığı ve Cinsiyetçi Şiddetle İlgili Görüşleri”. Galatasaray Üniversitesi İletişim Dergisi, 19:41-64.

Creswell, J. W. (2013). Nitel Araştırma Yöntemleri Beş Yaklaşıma Göre Nitel Araştırma ve Araştırma Desenleri Çev. Editörleri Mesut Bütün ve Selçuk Beşir Demir, Ankara: Siyasal Kitabevi.

Çilingir ÜK., Z. (2019). "Toplumsal Cinsiyet Stereotiplerinin Kadınlar Günü Reklamları Üzerinden Değerlendirilmesi”. Uluslararası İktisadi ve İdari Incelemeler Dergisi, 24: 1-16, https://doi.org/10.18092/ulikidince.519009

Dumanlı, D. (2011). "Reklamlarda Toplumsal Cinsiyet Kavramı ve Kadın İmgesinin Kullanımı; Bir İçerik Analizi”. Yalova Sosyal Bilimler Dergisi, 1(2):132-149.

Ekiz, D. (2013). Bilimsel araştırma yöntemleri. Anı yayıncılık, Ankara. 
Elgün, A., Yeniçeri Alemdar, M. (2017). "Üniversite Öğretmen Adaylarının Toplumsal Cinsiyet Rolleri Tutumlarına Yönelik Bir Araştırma: Ege Üniversitesi İletişim Fakültesi Örneği”. International Journal of Social Sciences and Education Research, 3(3): 1054-1067, https://doi.org/10.24289/ijsser.316874

Erdoğan, İ. (2004). Popüler Kültürün Ne Olduğu Üzerine, MEB. Basımevi (Eğitim Dergisi), Ankara.

Ersoy Çak, Ş. (2010). “Toplumsal Cinsiyet ve Feminizm Teorileri Bağlamında Türkiye'deki Reklam Filmleri ve Popüler Müzik Videoları". YEDİ, 4: 101-109.

Etiler, N., Zengin, Ü. (2015). “Televizyon Kanallarındaki Gündüz Programlarında Kadın Sağlığı ve Toplumsal Cinsiyete Bakışın Değerlendirilmesi”. Turkish Journal of Public Health, 13(2): 137-146, https://doi.org/10.20518/thsd.02616

Fidan, F. (2000). “Kapitalizmin Gelişme Sürecinde Kadının Çok Yönlü Konumu (Medya Örneği)”. Bilgi Sosyal Bilimler Dergisi, 1: 117-132.

Güllüoğlu, Ö. (2004). "Bir Kitle İletişim Aracı Olarak Televizyonun Popüler Kültür Ürünlerini Benimsetme ve Yayma İşlevi Üzerine Bir Değerlendirme”. Global Media Journal Turkish Edition, 2(4): 64-85.

Gündüz Kalan, Ö. (2010). "Reklamda Çocuğun Toplumsal Cinsiyet Teorisi Bağlamında Konumlandırılışı: 'Kinder' Reklam Filmleri Üzerine Bir İnceleme”. İstanbul Üniversitesi İletişim Fakültesi Dergisi, 1(38): 75-89.

Mamur, N. (2015). Resim-İş (Görsel Sanatlar) Öğretmen Eğitimi 'Müze Eğitimi ve Uygulamaları' Dersinde Görsel Kültür Kuramının Kullanımı. Education Sciences, 10(1): 29-53, https://doi.org/10.12739/nwsa.2015.10.1.1c0631

Mora, N. (2005). "Kitle İletişim Araçlarında Yeniden Üretilen Cinsiyetçilik ve Topluma Yansıması". Insan Bilimleri Dergisi, 2(1):1-7.

Mutlu, E. (2005). Globelleşme, Popüler Kültür ve Medya. Ankara. Ütopya Yayınları.

Öngen, B., Aytaç, S. (2013). "Üniversite Öğrencilerinin Toplumsal Cinsiyet Rollerine İlişkin Tutumları ve Yaşam Değerleri İlişkisi”. İstanbul Journal of Sociological Studies, 48: 1-18.

Parsa, A. F. (2007). İmgenin Gücü ve Görsel Kültürün Yükselişi. Fotografya Dergisi, 19, 1-10.

Serdaroğlu, U. (2010). İktisat ve Toplumsal Cinsiyet. Ankara: Eflatun Yayınevi.

Somyürek, S. (2014). "Öğretim Sürecinde Z Kuşağının Dikkatini Çekme: Arttırılmış Gerçeklik”. Eğitim Teknolojisi Kuram ve Uygulama, 4(1): 63-80, https://doi.org/10.17943/etku.88319

Tüzel, A. (2010). “Görsel Okuryazarl1k”. Türklük Bilimi Araştırmalarl, 27:691-705.

Vefikuluçay, D., Zeyneloğlu, S., Eroğlu, K., Taşkın, L. (2007). "Kafkas Üniversitesi Son Sınıf Öğrencilerinin Toplumsal Cinsiyet Rollerine İlişskin Bakış Açıları". Hacettepe Üniversitesi Hemşirelik Fakültesi Dergisi, 14(2):26-3.

Yağan Güder, S., Ay, A., Saray, F., Kılıç, İ. (2017). “Okul Öncesi Dönem Çocuklarının İzledikleri Çizgi Filmlerin Toplumsal Cinsiyet Kalıp Yargıları Açısından İncelenmesi: Niloya Örneği”. Eğitimde Nitel Araştırmalar Dergisi, 5(2): 96-111, https://doi.org/10.24315/trkefd.303686

Yeşil, F., Yıldırım, A. (2019). "Toplumsal Cinsiyet ve Medyadaki Söylemi: Evlilik Programları”. Selçuk Illetişim Dergisi, 12(1): 232-254, https://doi.org/10.18094/josc.412189 
Popüler Görsel Kültürde Toplumsal Cinsiyet Rollerinin İncelenmesi: Youtube Kanallarında... 367

Yıldırım, M. (2018). Yeni Medyada Ürün Yerleştirme: Youtube Kanalları ve "Youtuber'lar", Öztürk, G., Ekeni İ., Özdemir Çakır, H., Kocabay Şener, N., Tatlı, E., Eken, İ., Aydın, S. (ed.) içinde 2. Uluslararası İletişimde Yeni Yönelimler Konferansı Eğlence ve Ürün Yerleştirme, 3-4 Mayıs, 148-154.

Yüksel, N. A. (2006). "Otomobil Reklamlarında Yerleşik Toplumsal Cinsiyet Kalıpları: Türkiye'de Yayınlanan Televizyon Reklamları Üzerine Bir Çalışma”. Selçuk Üniversitesi Iletişim Fakültesi Akademik Dergisi, 4(2): 115-124. 